\title{
Performance of merging lines with uneven buffer capacity allocation: the effects of unreliability under different inventory-related costs
}

\author{
Sabry Shaaban ${ }^{1} \cdot$ Rodrigo Romero-Silva $^{2,3,4}$
}

Published online: 19 January 2020

(c) The Author(s) 2020

\begin{abstract}
This simulation study investigates whether machine efficiency, mean time to failure (MTTF) and mean time to repair (MTTR) significantly affect the performance of uneven buffer capacity allocation patterns for merging lines. Also studied is the trade-off between increasing throughput via bigger buffers and their associated inventory-related costs, since previous studies have shown that higher overall buffer capacity and higher average inventory content result in higher throughput. Results suggest that an ascending buffer allocation pattern (concentrating buffer capacity towards the end of the line) produces higher throughput in shorter, more unreliable lines; whereas the balanced pattern shows better performance in longer, more reliable lines. Increasing average buffer capacity per station and/or having higher average buffer content was found to be more cost-effective in lines with lower machine inefficiency, shorter MTTF and MTTR, and longer lines. Results differed between reliable and unreliable lines since reliable lines were particularly penalised by buffer capacity investiment/maintenance costs due to a relatively low increase in throughput resulting from the addition of extra buffer capacity.
\end{abstract}

Keywords Unreliable machines · Unbalanced lines · Average buffer level · Throughput $\cdot$ Inventory costs $\cdot$ Simulation

Rodrigo Romero-Silva

r.romerosilva@vu.nl; rromeros@up.edu.mx

Sabry Shaaban

shaabans@esc-larochelle.fr

1 Department of Strategy, ESC La Rochelle, 102 Rue de Coureilles, 17024 La Rochelle, France

2 Faculty of Engineering, Universidad Panamericana, Augusto Rodin 498, Insurgentes Mixcoac, 03920 Mexico City, Mexico

3 Department of Supply Chain Analytics, Vrije Universiteit Amsterdam, De Boelelaan 1105, 1081 HV Amsterdam, The Netherlands

4 Aviation Academy, Amsterdan University of Applied Sciences, Weesperzijde 190, 1097 DZ Amsterdam, The Netherlands 


\section{Introduction}

Parallel merging lines with no mechanical pacing are probabilistic mass production queueing systems in series. In these systems, stocks of partially finished items are usually transferred to a buffer storage location. A typical merging assembly line consists of two or more parallel serial production lines converging into a single assembly station, and the final assembly operation begins only when the components produced by all serial lines have arrived at the assembly station.

Merging lines that are unbalanced with respect to their buffer capacities are an important research and practice topic. Often, technical considerations restrict the amount of space available in the line, thereby making it difficult to allocate total buffer capacity evenly amongst individual buffers. Queueing networks with parallel, merging stages are common in a variety of manufacturing systems, computer networks, and supply chains (Hudson et al. 2015), hence studying the allocation of buffer space to meet desired performance objectives contributes to advancing both research and industry knowledge.

It is generally agreed that balancing both unpaced serial and merging production lines with evenly allocated buffer space along the line gives the best performance (Lambrecht and Segaert 1990; Shaaban et al. 2017). However some research (e.g. Conway et al. 1988; McNamara et al. 2016) has pointed to the value of incorporating more realistic characteristics into the task of line design since real life unpaced assembly lines can never be truly balanced and will inevitably suffer breakdown failures. Furthermore, previous research has shown that serial production line performance can be significantly affected by different mixtures of mean time to failure (MTTF), mean time to repair (MTTR) and buffer capacity (Battini et al. 2009; Colledani et al. 2010; Patti and Watson 2010; Assaf et al. 2014; Romero-Silva et al. 2019), complementing the overall efficiency rate (reliability) of the machines.

Therefore, this article addresses the twin issues of uneven buffer allocation and the impact of unreliability by simulating unreliable merging lines where buffers of unequal sizes are placed between workstations in a variety of patterns, line lengths, total buffer capacities and degrees of unreliability, in order to assess whether different degrees of unreliability affect the performance of buffer unbalancing. While the majority of studies on production line performance have focused on throughput performance ( $\mathrm{Li}$ et al. 2009), this study addresses the trade-off between the revenue generated by the merging line throughput and the inventory-related costs caused by the efforts to increase throughput (Hillier 2013).

The structure of this paper is as follows. A brief review of the relevant literature is presented in Sect. 2. Section 3 describes the motivation and study objectives. Subsequent sections discuss the methodology and experimental design details, and present the study results. The last two parts provide a discussion of the results and the study conclusions. 


\section{Literature review}

Most of the studies on parallel merging assembly lines (also known as fork-join or split-merge) have focused on line balancing (see for example, Akpınar and Bayhan 2011; Barron 2015; Purnomo et al. 2013; Sönmez et al. 2017). For a comprehensive literature review of merging line balancing methods, see Battaïa and Dolgui (2013), Sivasankaran and Shahabudeen (2014) and Weiss et al. (2018). Other studies, however, focused on merging lines with uneven buffer capacities. Merging line studies can be divided into two broad categories: reliable and unreliable merging lines. Below is a review of pertaining works.

Literature on uneven buffer allocation in reliable merging lines is sparse. Powell and Pyke (1998) presented general strategies on the efficient placement of buffers in unbalanced assembly systems with random processing times. Leung and Lai (2005) provided more guidance by discussing strategies on how to install parallel workstations for improved cycle times, compared to simple assembly systems. They concluded that off-line parallel systems are superior in reducing buffer requirements and reducing sensitivity to imbalance, compared to on-line and tunnel-gated systems. Applying interdisciplinary techniques to improve assembly systems, Bulgak (2006) used a genetic algorithm and simulation to yield maximum output, while optimising the buffers in merge and split unpaced assembly systems.

More recently, Shaaban et al. (2017) assessed the performance of unbalanced, reliable, unpaced merging lines with asymmetric buffer storage sizes. Lines were simulated with varying line lengths, mean buffer capacities and uneven buffer allocation configurations. They found that higher throughput (TR) and lower average buffer level (ABL) (as compared to an equivalent balanced merging line) were obtained when total available buffer capacity is allocated as evenly as possible and with a higher buffer capacity concentration towards the end of the line, respectively.

For unreliable merging lines, Gershwin (1991) first analysed a class of unreliable assembly/disassembly tree-network systems in which buffers are finite and machines perform operations when none of their upstream buffers are empty and none of their downstream buffers are full. An approximate decomposition method to estimate TR was presented at that time. Bhatnagar and Chandra (1994) later focused on three-station assembly systems, and used simulation to study the effect of variability due to unreliable stations and imperfect yields on assembly systems. More significant TR improvements were found from increasing the production rate of individual stations than from increasing the size of buffers. Subsequently, Jeong and Kim (2000) investigated buffered production systems with feeder stations merging into an assembly station. They developed heuristics to determine the line configuration which would bring a desired TR at a minimal cost with finite buffer sizes, and assumed exponential times to failure and repair, as well as exponential processing times.

Tan (2001) studied an unreliable merging system comprised of two stations in parallel with unbalanced processing rates feeding a common merge station. A decomposition method for determining the production rate and expected buffer contents was developed. Yuan and Liu (2005) focused on an unreliable assembly system where different types of components are processed by two separate work 
centres before merging into an assembly station with random breakdowns. They developed formulas for the probabilities of blocking, starvation, stockout, and station availability in steady state, and also obtained the probability distributions of blocking and failure times.

Liu and Li (2010) contributed to work on unreliable systems by proposing a decomposition algorithm to estimate the throughput of split and merge unreliable manufacturing systems with two parallel lines. They also presented three structural properties of split and merge manufacturing systems: conservation of flow, monotonicity (higher machine reliability and/or buffer size result in higher throughput) and reversibility (symmetrical split and merge lines are equivalent). More recently, Jia et al. (2016) studied the transient behaviour of assembly systems with merging serial lines, comprised of Bernoulli machines (subject to failure) with finite buffers. They derived formulas to efficiently measure TR, workin-process, and probability that any station will be blocked or starved, and also developed an analytical method for dealing with larger and more complex assembly systems, with multiple feeder lines and merge stations. Following this, Yegul et al. (2017) studied the optimal configuration of a real complex manufacturing system using a simulation-optimisation approach. Their study attempted to maximise the profit of the manufacturing system by optimising buffer sizes, number and speed of parallel machines, and allocation of workers to some of the system's stations. They considered stochastic setup times, processing times, time-to-failure and time-to-repair, as well as costs associated with labour, machine investments and inventory. They suggested that due to the very specific problem considered in their study, the allocation of machines and workers in a specific subset of stations were the most important factors in the profit function of the system.

Current work by Romero-Silva and Shaaban (2019) has suggested that an unbalanced assignment of buffer capacities along the line, i.e. concentrating buffer towards the central or final stations of the line, results in higher throughput for unreliable lines, while the throughput of reliable lines is better served with a balanced assignment of buffers. However, they did not assess the impact of different degrees of machine efficiency $(\varepsilon)$ and different values of MTTF and MTTR on the performance of a merging line, despite the fact that the influence of different production line design factors (e.g. buffer capacity) is highly dependent on $\varepsilon$, MTTF and MTTR (Colledani et al. 2010; Assaf et al. 2014; Tolio and Ratti 2018). Moreover, they did not investigate the profit-related trade-off between investing in additional buffer capacity to generate more throughput and the cost of that investment.

The above review reflects a history of merging line research that has mostly focused either on developing line balancing and mathematical optimisation methods, or on developing of analytical and approximation methods. To the best of our knowledge, there are no studies which integratively study the influence of both buffer allocation patterns and degrees of unreliability on the performance of TR and ABL in merging lines, considering inventory holding costs and buffer capacity investment costs. Therefore, the performance of unreliable merging lines with uneven buffer sizes is examined here to bridge this gap and contribute to both theory and practice. This study applies simulation and statistical analysis to assess if uneven buffer size 
allocation can generate better results than those obtained from balanced buffer allocation along the line, considering different degress of unreliability.

\section{Motivation and research questions}

This paper studies unreliable merging assembly lines with a single imbalance source, namely, uneven buffer capacity allocation (and specifically, distributing total available buffer capacity asymmetrically along the buffers with different degrees of unreliability), while keeping identical mean service times (MTs) and coefficients of variation $(\mathrm{CV})$ throughout. As there is a paucity of research on the behaviour of unreliable merging lines, the results presented here help improve our understanding of how uneven buffer allocation and unreliability can impact performance.

Furthermore, although it has been shown that both higher buffer capacity (Conway et al. 1988; Tan 1998; Kalir and Sarin 2009) and higher work-in-process (from Little's Law-Maxwell 1970) result in higher throughput, few studies have addressed the impact of additional inventory-related costs on the overall profit of the firm (see e.g. Hillier and Hillier 2006; Hillier 2013). Therefore, to assess the impact of these costs, this study considers the effect of inventory holding costs and buffer capacity investment/maintenance costs on the performance of buffer capacity allocation patterns.

The research questions are:

(1) Which buffer allocation patterns provide the best performance in terms of TR and ABL, considering different values of machine unreliability, MTTF and MTTR? Do different degrees of unreliability influence the performance of buffer allocation patterns?

(2) What are the relative impacts of buffer allocation patterns, overall line buffer capacity, line length, machine unreliability, MTTF and MTTR on the performance of merging lines?

(3) Do the characteristics of a merging line (length, unreliability, MTTF and MTTR) have an influence on performance when considering inventory-related costs?

As these questions have not been explicitly addressed in previous unreliable merging line studies, the objective of this paper is to provide more insight into the effect of unreliability and buffer capacity allocation on the performance of merging lines.

\section{Methodology and design of simulation experiments}

Due to their large state spaces, exact solutions of merging line systems can only be obtained by analysing the underlying Markov chain using numerical methods, which are not computationally feasible for lines longer than three stations and for non-exponential distributions. To address these constraints, computer simulation is 
applied in many cases to study such systems. Discrete-event simulation was deemed the most appropriate tool for this study because of the severe limitations of mathematical approaches in dealing with more realistic and complex merging lines. The Simio 10.165 simulation software (Kelton et al. 2014) was used to study the behavior of the unreliable, unbalanced merging lines at the heart of this paper.

\subsection{Model description}

Unpaced, unreliable merging systems with two parallel lines are studied in this paper. The two parallel lines ( $\mathrm{A}$ and $\mathrm{B}$ ) have $\mathrm{N}$ number of stations and converge into a Final Assembly station, which needs one component from each parallel line to start the final operation. Upstream stations $\left(S_{i A}, S_{i B}\right)$ feed downstream stations $\left(S_{(i+1) A}, S_{(i+1) B}\right)$ through a buffer $\left(B_{i A}, B_{i B}\right)$ with capacity $B C_{i A}\left(B C_{i B}\right)$. The Final Assembly station is fed by buffers $\mathrm{F}_{1}$ and $\mathrm{F}_{2}$, which are fed, respectively, by stations $S_{N A}$ and $S_{N B}$.

If $B_{i A}$ is full and preceding station $S_{i A}$ has completed a task, then $S_{i A}$ will be blocked until $B_{i A}$ has space. If $S_{(i+1) A}$ has completed a task but preceding buffer $B_{i A}$ is empty, then $S_{(i+1) A}$ will be starved. The first station of a parallel line $\left(S_{1 A}\right.$ and $\left.S_{1 B}\right)$ is never starved and the Final Assembly station is never blocked. Both parallel lines A and $\mathrm{B}$ have identical behaviour.

In addition, all stations have the same unreliability profile, depending on the experimental setting. MTTFs are modelled based on machine operation time, as opposed to production running time.

An example of two merging lines with $\mathrm{N}=5$ and $\mathrm{BC}=2$ is shown in Fig. 1, where the Final Assembly station is starved (in grey) because it has not received a component part from parallel line $\mathrm{B}$ ( $\mathrm{F}_{2}$ is empty). $S_{3 B}$ (shown in red) has failed and is being repaired, causing $S_{4 B}$ and $S_{5 B}$ to be starved and $S_{1 B}$ and $S_{2 B}$ (shown in yellow) to be blocked, as $\mathrm{B}_{1 \mathrm{~B}}$ and $\mathrm{B}_{2 \mathrm{~B}}$ are full.

For each station, the mean processing time (MT) was set at 10 time units, while the coefficient of variation (CV) was fixed at 0.274, in line with Slack's (1982) contention that a $\mathrm{CV}$ of 0.274 represents the average value found in real manual unpaced production lines. The processing times of all stations follow a Weibull probability distribution with a location parameter of 5.78 and a shape parameter equal to 4.702 .

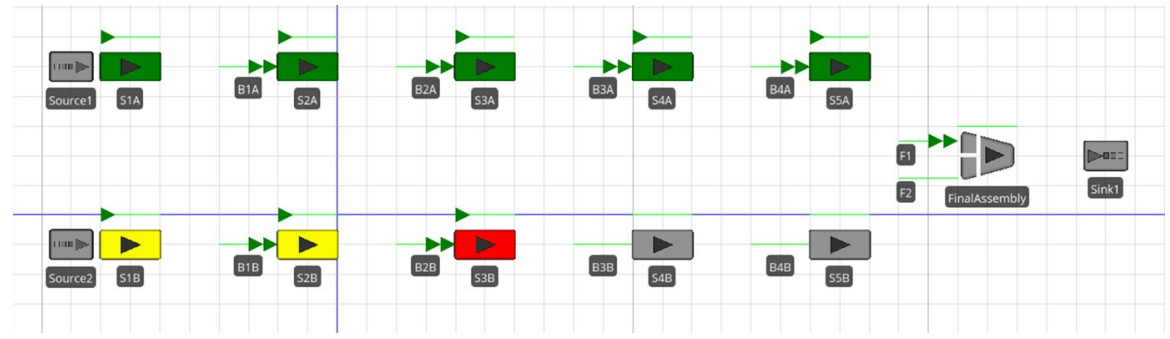

Fig. 1 Screenshot of a Simio model for two merging lines with $\mathrm{N}=5$ and $\mathrm{BC}=2$ 
Moreover, just one product type is made, no defective items are produced, there are no changeovers/setups and the time to move work units in/out of the buffers is zero.

The above assumptions are in agreement with those stated in previous simulation studies (e.g. El-Rayah 1979; Powell 1994; Sabuncuoglu et al. 2006) as well as empirical findings (Weiss et al. 2018).

\subsection{Research design}

This investigation utilises a full factorial experimental design, which permits the consideration of all desired levels of a given factor, together with all levels of every other factor, to measure the impact of independent variables on dependent variables.

\subsubsection{Experimental factors}

In this paper, the independent variables (factors) studied are:

- Number of stations (line length), N.

- Mean capacity of each buffer, BC, or equivalently, total buffer capacity of the line divided by the number of buffers.

- Buffer allocation patterns, $\mathrm{P}_{\mathrm{A}}$ and $\mathrm{P}_{\mathrm{B}}$, for parallel lines $\mathrm{A}$ and $\mathrm{B}$, respectively.

- Degree of machine unreliability, which is made up of two components:

- Machine efficiency or (un)reliability

$$
\varepsilon=\frac{M T T F}{M T T F+M T T R}
$$

\section{- Duration of MTTF and MTTR $(\alpha)$}

The use of fixed patterns of uneven mean buffer size allocation is a well-established method of investigation in previous literature (e.g. Anderson et al. 1973; Das et al. 2010, 2012; Davis 1965; Hutchinson et al. 1997; Smith and Brumbaugh 1977; Wyche and Wild 1977) to evaluate their effect on production line behaviour. Furthermore, all independent variables were chosen because of their demonstrated influence on TR and ABL (Conway et al. 1988; Hillier and So 1991; Tan 1998; Jacobs et al. 2003; Kalir and Sarin 2009).

Three $\mathrm{N}$ levels were selected (5,8 and 11) to account for odd and even numbers and for longer lines $(\mathrm{N}>9)$, as it has been shown that different patterns can behave differently for longer lines (Lau 1992). Two BC levels were considered (2 and 6). These values were selected such that $\mathrm{BC} \neq 0$, while taking into account that, over a certain level of buffer space, the law of diminishing returns sets in (Schmenner and Swink 1998), leading to negligible improvement in TR as buffer size increases. Note also that, in order to ensure comparability, the patterns for $\mathrm{BC}=6$ are equivalent to those for $\mathrm{BC}=2$.

Five different uneven buffer capacity allocation policies for lines A and B were considered: balanced, ascending, descending, bowl and inverted bowl. The patterns used in this study correspond to those used in some previous publications 
(Shaaban et al. 2017; Romero-Silva and Shaaban 2019). The experimental values used in the simulation analysis can be found in the "Appendix" (Table 3).

MTTF and MTTR were modelled with an exponential distribution, based on the empirical results of Inman (1999). Also based on Inman (1999), a minimum realistic $\varepsilon$ of $70 \%$ was selected, while $90.9 \%$ was regarded as a typical value for $\varepsilon$, i.e. [MTTF] 1000/([MTTF] $1000+$ [MTTR] 100)], in accordance with previous work (Altiok and Stidham 1983; Hopp and Simon 1993; Inman 1999).

Three levels of $\alpha(1,2$ and 3) were estimated for MTTF and MTTR. $\mathrm{MTTF}_{\alpha \varepsilon}$ and $\mathrm{MTTR}_{\alpha \varepsilon}$ model the MTTF and MTTR values used for experiments with machine efficiency $\varepsilon$ and degree (length) of duration $\alpha$. An MTTF $=1000$ and MTTR $=100$ were considered as a medium level $\alpha(\alpha=2)$ for $\varepsilon=90.9 \%$. Short MTTFs for a specific value of $\varepsilon\left(\mathrm{MTTF}_{1 \varepsilon}\right)$ were then calculated as $\mathrm{MTTF}_{1 \varepsilon}=1 / 2 \mathrm{MTTF}_{2 \varepsilon}$, while longer MTTFs were calculated as $\mathrm{MTTF}_{3 \varepsilon}=2 \mathrm{MTTF}_{2 \varepsilon}$. For example, $\mathrm{MTTF}_{1,90.9 \%}=500$ and $\mathrm{MTTF}_{3,90.9 \%}=2000$. The calculations were equivalent for $\mathrm{MTTR}_{1 \varepsilon}$ and $\mathrm{MTTR}_{3 \varepsilon}$.

Finally, based on the value of $\mathrm{MTTF}_{2,90.9 \%}, \mathrm{MTTF}_{2,70 \%}$ was calculated by assuming that a lower efficiency will be the result of a proportionally shorter mean time to failure, whereas a higher efficiency will be the result of a proportionally higher mean time to failure. For instance,

$$
\mathrm{MTTF}_{2,70 \%}=\frac{0.7}{0.909} \mathrm{MTTF}_{2,90.9 \%}=770
$$

For parallel lines A and B, the levels (experimental values) are summarised in Table 1 below.

Thus, taking into account all levels for the 6 factors (considering $\mathrm{P}_{\mathrm{A}}$ and $\mathrm{P}_{\mathrm{B}}$ as two different factors), a total of $3 * 2 * 5 * 5 * 3 * 2+3 * 2 * 5 * 5=1050$ $\left(\mathrm{N} * \mathrm{BC} * \mathrm{PA}^{*} \mathrm{~PB} *(\varepsilon<1) * \alpha\right.$ [for unreliable lines] $+\mathrm{N}^{*} \mathrm{BC} * \mathrm{PA} * \mathrm{~PB}$ [for reliable lines]) experimental points were studied.

Table 1 Experimental factors and their levels

\begin{tabular}{|c|c|c|c|c|}
\hline Factor & \multicolumn{4}{|c|}{ Levels (experimental values) } \\
\hline Number of stations per parallel line $(\mathrm{N})$ & \multicolumn{4}{|l|}{5,8 and 11} \\
\hline Mean buffer capacity (BC) & \multicolumn{4}{|l|}{2 and 6} \\
\hline Buffer allocation patterns $\left(\mathrm{BP}: \mathrm{P}_{\mathrm{A}}\right.$ and $\left.\mathrm{P}_{\mathrm{B}}\right)$ & \multicolumn{4}{|c|}{$\begin{array}{l}\text { Balanced }(-) \text {, ascending }(/) \text {, descending }(\backslash) \text {, bowl }(\mathrm{V}) \\
\text { and inverted bowl }(\Lambda)\end{array}$} \\
\hline Machine unreliability $(\varepsilon)$ & $\begin{array}{l}\text { MTTF }_{\alpha \varepsilon}, \text { MTTR } \\
\quad \text { (minutes) }\end{array}$ & $70 \%$ & $90.9 \%$ & $100 \%$ \\
\hline \multirow[t]{4}{*}{ Degree of duration of MTTF and MTTR $(\alpha)$} & Zero $(0)$ & NA & NA & 0 \\
\hline & Short (1) & 385,165 & 500,50 & NA \\
\hline & Medium (2) & 770,330 & 1000,100 & NA \\
\hline & Long (3) & 1540,660 & 2000,200 & NA \\
\hline
\end{tabular}




\subsubsection{Performance measures}

Two main performance measures were considered in this study: throughput rate (TR) and average buffer level per station (ABL). TR is the most commonly studied performance measure ( $\mathrm{Li}$ et al. 2009) due to its importance for high-volume industries, whereas ABL is essentially a cost-related measure that is more relevant for industries with a focus on keeping stocks at low levels. TR represents the number of finished goods exiting the Final Assembly station, while ABL measures the average amount of inventory at any given time in all the buffers of the line.

Similar to Hillier's (2013) approach, a profit function $(Z)$ was used to evaluate the performance in terms of both TR and ABL, whereby a unit produced by the system generates revenue $(r)$, while an inventory unit stored in a period of time incurs a holding cost $\left(c_{1}\right)$. Since additional expenses are often incurred to maintain certain levels of buffer capacity (Tempelmeier 2003), investment and/ or maintenance costs per average unit of buffer capacity per time unit $\left(c_{2}\right)$ were also considered.

However, to simplify the analysis, both $c_{1}$ and $c_{2}$ were considered as relative values of $r$, leading to simplified versions of holding $\left(h=c_{1} / r\right)$ and investment/ maintenance $\left(i=c_{2} / r\right)$ costs, resulting in the following profit function:

$$
Z=T R-h A B L-i B C
$$

Dunnett's $t$ test and Tukey's HSD test were carried out to statistically assess the differences among the experimental results. ANOVA tests were carried out to determine the statistical significance of each factor for the resulting TR and ABL. The ' $R$ ' package (The R Foundation 2016) agricolae was utilised to statistically analyse TR and ABL data.

\subsection{Simulation run parameters}

To generate representative simulation data, a suitable warm-up/transient period is needed to ensure that observations are very close to normal operating conditions. Law (2014) suggested running a preliminary system simulation, selecting one output variable for observation. A trial procedure for this system found that after an initial simulation run of 20,000 min, acceptable steady-state behaviour for TR was established. In this regard, all data gathered during the first 20,000 min were discarded, and 300 independent runs of 120,000 min each were carried out, excluding the first 20,000 min of non-steady state data. Thus, TR and ABL estimations presented in this paper are in fact the average values of TR and $\mathrm{ABL}$ over the 300 replications.

Moreover, to reduce experimental variance, specific random number streams were assigned to each random variable (factor) at each station, i.e. processing times, time-to-failure and time-to-repair probability distributions; and common random numbers were used for each stream throughout the 300 replications. 


\section{TR and $A B L$ results}

To show the global effect of each pattern on TR and simplify the analysis, average TR results for experiments with different $\mathrm{P}_{\mathrm{A}}$ were calculated. For instance, results for a balanced $\mathrm{P}_{\mathrm{A}}(-)$ were calculated as the average TR of experiments with patterns $(-,-),(-, /),(-),,(-, \Lambda)$ and $(-, \mathrm{V})$. Furthermore, as TR results have very different magnitudes for different $\varepsilon$ and $\alpha$ values, Fig. 2 shows "normalised" TR results (nTR), which were calculated by dividing the average TR results of each $\mathrm{P}_{\mathrm{A}}$ by the average overall TR value of all experiments with the same $\mathrm{N}, \varepsilon, \alpha$ and $\mathrm{BC}$ values. It is worth noting that results regarding $\mathrm{P}_{\mathrm{B}}$ are not shown as they were equivalent. Full TR results with their corresponding Dunnett's and Tukey's tests results can be found in the "Appendix", Tables 4 and 5, respectively.

Results shown in Fig. 2 suggest that the performance of buffer allocation patterns is highly dependent on the values of $\mathrm{N}, \varepsilon$ and $\alpha$. For example, the ascending $\mathrm{P}_{\mathrm{A}}(/)$ performed very well with $\varepsilon=70 \%$, which was only outperformed by the balanced pattern when $\mathrm{BC}=6$ and $\alpha<3$ for lines with $\mathrm{N} \geq 8$. Figure 2 also suggests that the balanced pattern performs better with increasing values of $\mathrm{N}, \mathrm{BC}$ and $\varepsilon$, while the ascending pattern performs better with decreasing values of $\mathrm{N}, \mathrm{BC}$ and $\varepsilon$, and increasing values of $\alpha$. These results are also confirmed by Tables 4 and 5 , as experiments with the pattern $(/, /)$ were found to have statistically significant differences with the control (balanced pattern) only when $\varepsilon=70 \%$. Thus, increasing values of $\varepsilon$ resulted in lesser relative differences among the patterns, suggesting that the effect of buffer allocation patterns on TR is highly dependent on the reliability of the machines.

On the other hand, the descending $\mathrm{P}_{\mathrm{A}}(\backslash)$ was the worst pattern in terms of TR for all scenarios, a result confrmed by Tables 4 and 5 as experiments with the pattern $(\backslash, \backslash)$ had the lowest TR in all experimental conditions. Interestingly, the bowl $(\mathrm{V})$ and inverted bowl patterns $(\Lambda)$ changed their relative performance with increasing $\mathrm{N}$ values, since the $(\Lambda)$ pattern was almost on par with the good performance of (-) when $\mathrm{N}=8$ for some scenarios; whereas the (V) pattern seemed to have an overall good performance for scenarios with $\mathrm{N}=11, \mathrm{BC}=6$ and $\alpha \geq 2$.

(a)

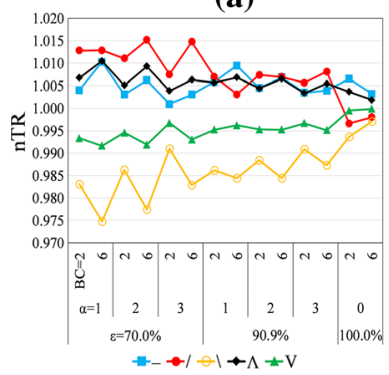

(b)

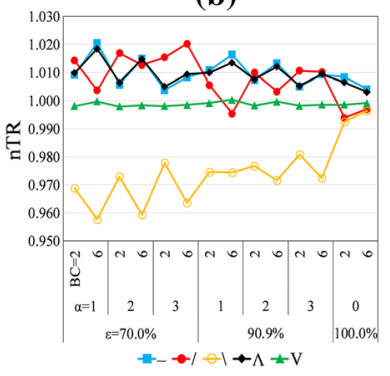

(c)

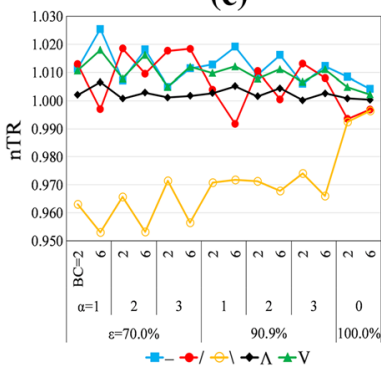

Fig. 2 nTR results for $\mathrm{P}_{\mathrm{A}}$ with $\mathbf{a} \mathrm{N}=5, \mathbf{b} \mathrm{N}=8$ and $\mathbf{c} \mathrm{N}=11$ 
Similar to Fig. 2, Fig. 3 shows the normalised ABL results (nABL) showing the relative performance in each experimental scenario (different values of $N, \varepsilon, \alpha$ and BC) per $\mathrm{P}_{\mathrm{A}}$.

Figure 3 suggests that $\mathrm{ABL}$ results are more consistent than TR results in terms of $\mathrm{P}_{\mathrm{A}}$ performance, since the ascending pattern is always the best-performing (with lower $\mathrm{ABL}$ ) and the descending pattern is always the worst. Tables 6 and 7 in the "Appendix" confirm this conclusion by showing that the best pattern in terms of $\mathrm{ABL}$ for all scenarios is $(/, /)$, while the worst pattern for almost all scenarios is $(\backslash, \backslash)$. Contrary to the interaction effect between $\mathrm{P}_{\mathrm{A}}$ and $\varepsilon$ on TR, higher values of $\varepsilon$ resulted in a higher influence of $\mathrm{P}_{\mathrm{A}}$ on $\mathrm{ABL}$, especially with lower values of $\mathrm{N}$.

The Analysis of Variance test (Table 2) shows that both reliability-related factors $(\varepsilon$ and $\alpha$ ) have the highest influence on TR, followed by BC and the interaction between $\varepsilon$ and $\alpha$. As seen in Figs. 2 and 3, the interactions between BP and BC, N, $\varepsilon$ and $\alpha$ are also significant, albeit they have a lower effect on TR when compared to single factors. For ABL, BC is the most important factor, followed by BP and the interaction between $\mathrm{BP}$ and $\mathrm{BC}$. Therefore, the performance of $\mathrm{ABL}$ is more dependent on selecting a good (bad) pattern.

\section{Profit results}

While TR and ABL results are relevant in isolation for some firms with a concern for either maximising revenue or minimising inventory costs, most firms are more interested in finding a balance between revenue and costs via a profit function. For this reason, studying the effect of buffer allocation patterns on the combined performance of TR and ABL provides a deeper insight into the implications of unbalanced buffer allocation.

Consequently, the profit function $(Z)$, defined in Eq. (3), was used to study the combined performance of TR and ABL, as it takes into consideration inventory holding costs and buffer capacity investment/maintenance costs while generating revenue via the production rate. Therefore, the best pattern for different values of $\mathrm{N}$, $\varepsilon$ and $\alpha$ will be the pattern which sufficiently increases TR, outweighing the costs of $\mathrm{ABL}$ and $\mathrm{BC}$.

(a)

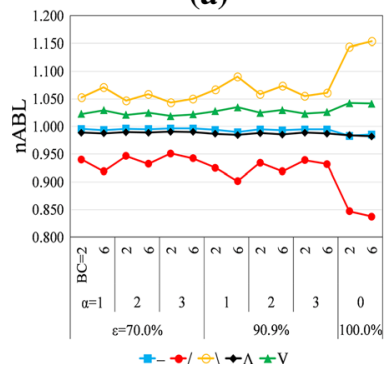

(b)

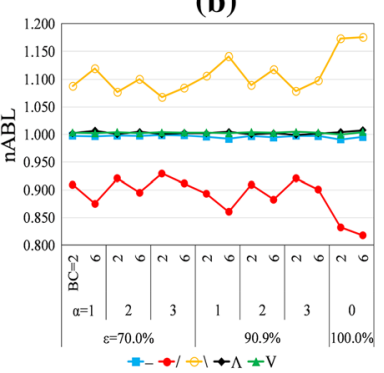

(c)

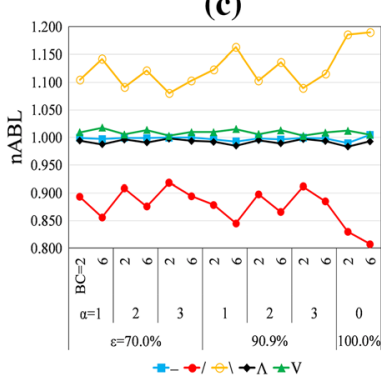

Fig. 3 nABL results for $\mathrm{P}_{\mathrm{A}}$ with $\mathbf{a} \mathrm{N}=5, \mathbf{b} \mathrm{N}=8$ and $\mathbf{c} \mathrm{N}=11$ 


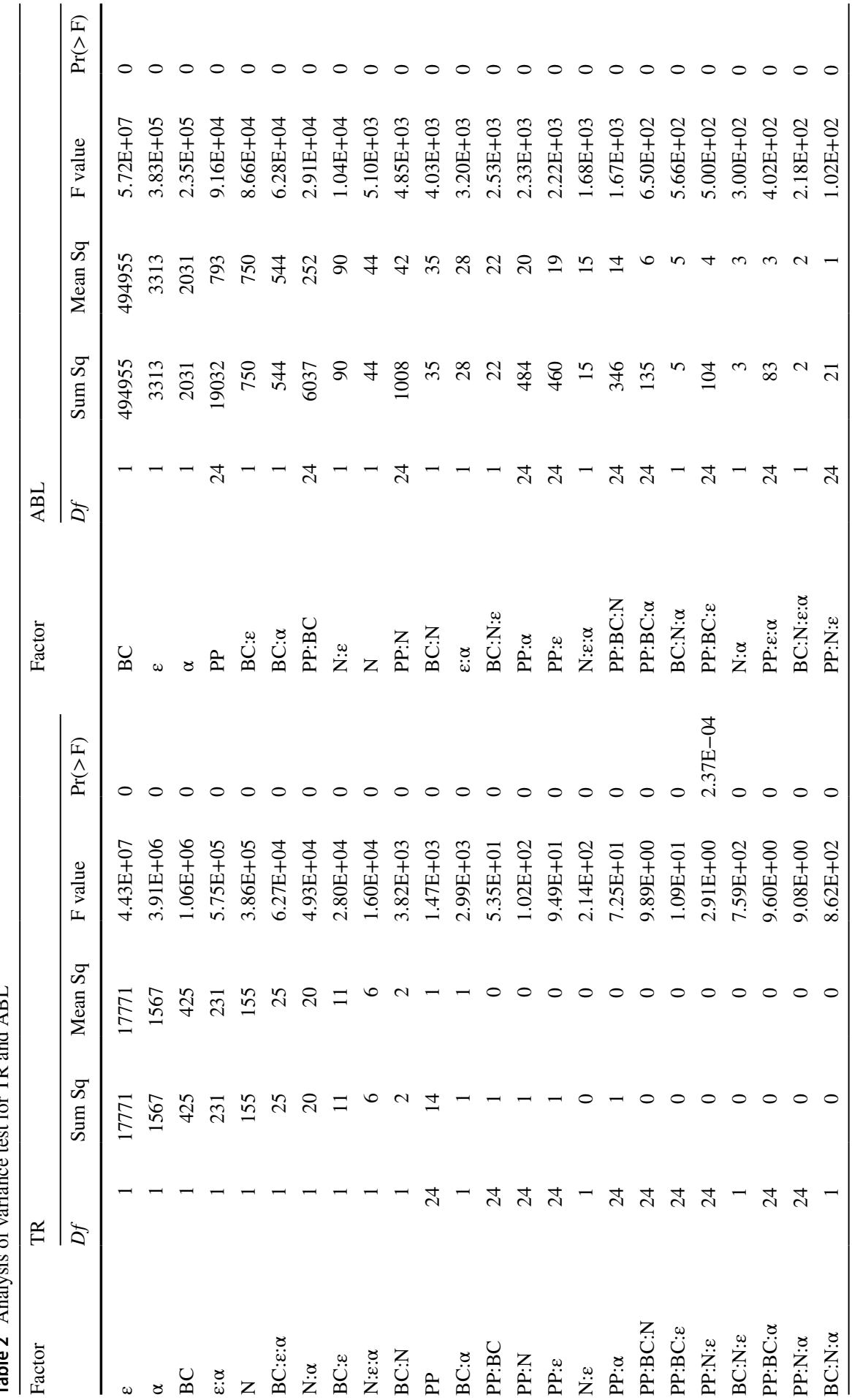




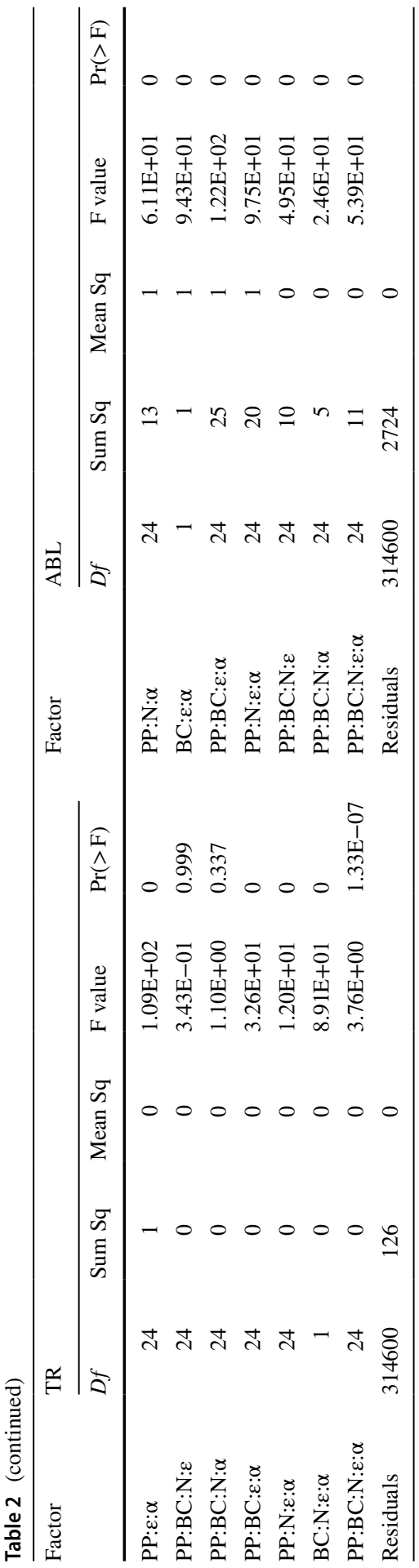


For each merging line configuration (with equal values of $\mathrm{N}, \mathrm{BC}, \varepsilon$ and $\alpha$ ), there is one pattern that achieves the highest $\mathrm{TR}\left(\mathrm{BP}_{\operatorname{maxTR}}\right)$ and one pattern that generates the lowest $\mathrm{ABL}\left(\mathrm{BP}_{\min \mathrm{ABL}}\right)$. However, finding which of the two is the best in terms of $Z$ will depend on whether TR or ABL carries more "weight" in the profit function. Such weight is measured by $h$ (the inventory holding cost). Therefore, to determine the threshold holding cost $\left(h_{0}\right)$ under which $\mathrm{BP}_{\text {maxTR }}$ produces the same performance as $\mathrm{BP}_{\operatorname{minABL}}$, the profits resulting from each pattern were equalled as follows:

$$
Z_{B P_{\text {maxtR }}}=T R_{B P_{\text {max }}}-h A B L_{B P_{\text {max }} T R}-i \mathrm{BC}=Z_{B P_{\text {minA } A L}}=T R_{B P_{\text {minA } A L}}-h A B L_{B P_{\text {minABL }}}-i \mathrm{BC}
$$

where $Z_{B P_{\max T R}}$ is the profit resulting from the buffer allocation pattern attaining the maximum TR, $T R_{B P_{\max T R}}$ is the maximum TR per scenario, $A B L_{B P_{\max }}$ is the ABL resulting from the $\mathrm{BP}$ that reached maximum $\mathrm{TR}, \mathrm{BC}$ is the average buffer capacity for a particular experimental scenario; $Z_{B P_{\min A B L}}$ is the profit obtained from the BP with minimum $\mathrm{ABL}, A B L_{B P_{\text {minABL }}}$ is the minimum $\mathrm{ABL}$ per scenario, and $T R_{B P_{\text {minABL }}}$ is the TR generated from using the $\mathrm{BP}$ which resulted in the minimum ABL.

Since the term $i \mathrm{BC}$ is equal for both sides of the equation when $\mathrm{BC}$ is equal among experiments; then,

$$
h_{0}=\frac{T R_{B P_{\max T R}}-T R_{B P_{\min A B L}}}{A B L_{B P_{\text {maxTR }}}-A B L_{B P_{\text {minABL }}}}
$$

This means that when $h>h_{0}$ for a particular manufacturing environment, $\mathrm{BP}_{\operatorname{minABL}}$ has a higher $Z$ than $\mathrm{BP}_{\text {maxTR }}$ because the system is better off minimising holding costs, as they are too high to overcome with higher TR; whereas when $h<h_{0}, \mathrm{BP}_{\operatorname{maxTR}}$ will result in higher $Z$ than $\mathrm{BP}_{\operatorname{minABL}}$ because inventory holding costs are not as penalising. For example, an $h_{0}=0.019$ shown in Fig. 4a for $\mathrm{N}=11, \mathrm{BC}=6, \varepsilon=70 \%$ and $\alpha=1$, means that if $h=0.02, \mathrm{BP}_{\operatorname{minABL}}(/, /)$ has a higher $Z$ than $\mathrm{BP}_{\operatorname{maxTR}}(-,-)$ since $Z_{(/, /)}=0.2812-0.02(2.7279)=0.2266>Z_{(-,-)}=0.3010-0.02(3.7827)=0.2253$; whereas if $h=0.018, \mathrm{BP}_{\operatorname{minABL}}(/, /)$ has a lower $Z$ than $\mathrm{BP}_{\operatorname{maxTR}}(-,-)$ since $Z_{(/, /)}=0.2812-0.018(2.7279)=0.2321<Z_{(-,-)}=0.3010-0.018(3.7827)=0.2329$.

(a)

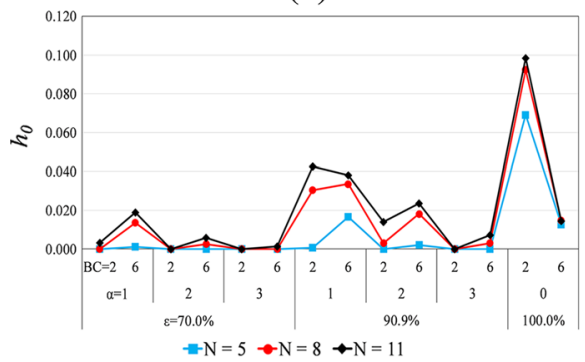

(b)

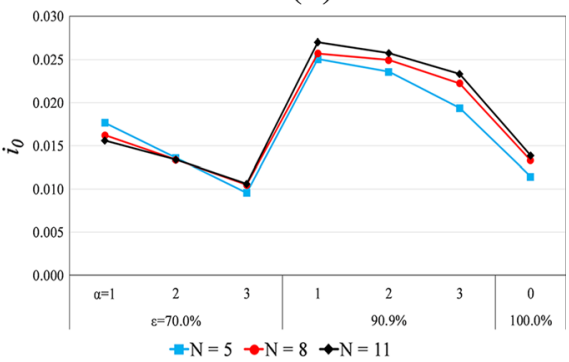

Fig. 4 a $h_{0}$ and $\mathbf{b} i_{0}$ values for all experimental scenarios 
Similar to the notion of $h_{0}$, a threshold investment/maintenance cost $\left(i_{0}\right)$ was calculated in order to assess at which point additional buffer capacity starts to be too costly to justify its additional output in terms of TR, as it has been shown that higher buffer capacity results in higher TR (Tan 1998; Kalir and Sarin 2009). In order to calculate $i_{0}$ it was assumed that $Z$ was equal for scenarios with equal $\mathrm{N}, \varepsilon$ and $\alpha$ values, but different BC values. It was also assumed that $h$ was equal to zero in order to have a straightforward reference point for analysing the buffer capacity investment costs. Thus,

$$
T R_{B P \min A B L, \mathrm{BC}_{2}}-i_{0} \mathrm{BC}_{2}=T R_{B P \min A B L, \mathrm{BC}_{6}}-i_{0} \mathrm{BC}_{6}
$$

where $\mathrm{TR}_{\mathrm{BPmin} A \mathrm{BL}, \mathrm{BC} 2}$ is the $\mathrm{TR}$ reached for a $\mathrm{BC}=2$ while applying $\mathrm{BP}_{\min \mathrm{ABL}}$ and $\mathrm{TR}_{\mathrm{BPminABL}, \mathrm{BC} 6}$ is the $\mathrm{TR}$ reached for a $\mathrm{BC}=6$ using $\mathrm{BP}_{\operatorname{minABL}}$ for a specific scenario.

Therefore,

$$
i_{0}=\frac{T R_{\mathrm{BC}_{6}}-T R_{\mathrm{BC}_{2}}}{6-2}
$$

It is worth noting that all variables in Eqs. (6) and (7) consider experimental scenarios with equal values of $\mathrm{N}, \varepsilon$ and $\alpha$. Moreover, $\mathrm{BP}_{\operatorname{minABL}}$ was selected as the pattern considered for these equations because the BP with minimum experimental ABL produces the highest $Z$ when $h=0$.

Thus, lower $i_{0}$ values for a given set of $\mathrm{N}, \varepsilon$ and $\alpha$ values represent higher penalties for investing in higher buffer capacity, while higher $i_{0}$ values depict lower profit penalties with high $i$ values. Similarly to $h_{0}$, a higher value of $i$ than $i_{0}$ for a given line configuration suggests that it is more profitable not to invest in higher buffer capacity, i.e. stay at $\mathrm{BC}=2$; whereas a lower value of $i$ than $i_{0}$ means that is profitable to invest in the additional 4 buffer spaces, i.e. a $\mathrm{BC}=6$. For instance, an $i_{0}=0.010$ shown in Fig. $4 \mathrm{~b}$ for $\mathrm{N}=5, \varepsilon=70 \%$ and $\alpha=3$, means that a buffer investment/maintenance cost of $i=0.011$ results in a decision of staying with $\mathrm{BC}=2$ as $\quad Z_{B C=2}=0.2055-0.011(2)=0.1835>Z_{B C=6}=0.2438-0.011(6)=0.1777$; whereas if $i=0.009$, then $\mathrm{BC}=6$ is more profitable than $\mathrm{BC}=2$ since $Z_{B C=2}=0.2055-0.009(2)=0.1875<Z_{B C=6}=0.2438-0.009(6)=0.1898$.

Results from Fig. 4a show that higher values of $\mathrm{N}$ resulted in higher values of $h_{0}$, which suggests that patterns that increase TR are more relevant for longer lines than for shorter lines; whereas patterns that reduce ABL produce better overall results for shorter lines in terms of $Z$. Furthermore, higher values of $\varepsilon$ and lower values of $\alpha$ (shorter MTTF and MTTR) result in higher values for $h_{0}$, suggesting that higher machine reliability results in a reduced impact of inventory holding costs.

Further analysis of Fig. 4a shows that scenarios with smaller buffer capacity $(\mathrm{BC}=2)$ have lower values of $h_{0}$, suggesting that profit in these scenarios is highly penalised by $\mathrm{ABL}$ and that a pattern that reduces ABL produces higher $Z$ for most inventory holding costs values. The opposite is true for scenarios with $\mathrm{BC}=6$, since $Z$ is less penalised by $\mathrm{ABL}$ as $\mathrm{BP}_{\operatorname{maxTR}}$ (the pattern producing the maximum TR) results in a higher $Z$ even for higher values of $h$. This suggests that the extra TR produced by the extra ABL (resulting from higher BC capacity) 
allows for $\mathrm{BP}_{\operatorname{maxTR}}$ to be more relevant when $\mathrm{BC}=6$. An $h_{0}=0$ indicates that the corresponding scenario, e.g. $\mathrm{N}=5, \varepsilon=70.0 \%, \alpha=2$ and $\mathrm{BC}=2$, produces the highest profit by selecting the buffer allocation pattern that reduces ABL, irrespective of the value of $h$.

The only exception to this general $h_{0}$ behaviour occurs in scenarios with reliable merging lines $(\varepsilon=100 \%)$, or with $\mathrm{N}=11, \varepsilon=90.9 \%$ and $\alpha=1$, since $h_{0}$ is higher for scenarios with $\mathrm{BC}=2$ than for experiments with $\mathrm{BC}=6$. This might be due to the fact that the added ABL produced by higher BC capacity does not result in a sufficiently additional TR to overcome the inventory holding costs. Therefore, for reliable lines with $\mathrm{BC}=2, \mathrm{BP}_{\operatorname{maxTR}}$ is more relevant than $\mathrm{BP}_{\operatorname{minABL}}$ with respect to $Z$.

Results regarding $i_{0}$ (see Fig. $4 \mathrm{~b}$ ) suggest that higher values of $\alpha$ (longer MTTF and MTTR) produce a higher investment/maintenance penalty (lower $i_{0}$ values) for systems with higher buffer capacities, which means that the additional throughput produced by the added buffer capacity is more cost-effective for shorter MTTF and MTTR than for longer ones. Similarly, systems with $\varepsilon=90.9 \%$ were less penalised in terms of profit by higher buffer capacities than systems with $\varepsilon=70 \%$, suggesting that the extra throughput produced by the increased buffer capacity is more costeffective when reliability is $90.9 \%$ than when reliability equals $70 \%$.

An exception to this observation occurred for the reliable merging lines results, as $i_{0}$ values for reliable lines were lower than for experiments with $\varepsilon=90.9 \%$ and $\varepsilon=70.0 \%$ with $\alpha=1$, suggesting that even with low buffer capacity investment/maintenance costs, small buffer capacities will be better in terms of profit performance for reliable lines than larger buffer capacities. This result might be caused by the fact that the relative difference between the throughput generated by lines with small and big buffers is smaller for reliable lines than for unreliable ones. For instance, considering $\mathrm{N}=5$ and a balanced $\mathrm{BP}(-,-)$, the increase in TR between a line with $\mathrm{BC}=2$ and a line with $\mathrm{BC}=6$, considering $\varepsilon=70 \%$ and $\alpha=1$, is $28 \%$; whereas for a reliable line with $\varepsilon=100 \%$, the relative increase in TR between a line with $\mathrm{BC}=2$ and a line with $\mathrm{BC}=6$ is only $4 \%$ (see Table 4 in the "Appendix").

In addition, Fig. $4 \mathrm{~b}$ shows that longer merging lines result in higher $i_{0}$ values, for the most part, suggesting that longer lines could be less sensitive in terms of $Z$ to higher buffer capacity investment/maintenance costs than shorter lines.

Finally, to investigate the relationship between $h$ and $i$ values in terms of the profit function for different buffer capacity investments levels, Fig. 5 shows a comparison of the suface plots of $Z$ between merging lines with $\mathrm{BC}=2$ (in blue) and merging lines with $\mathrm{BC}=6$ (in orange) for various values of $h$ and $i$, taking $\mathrm{N}=5$ as an example.

Figure 5 shows similar results than those for Fig. 4b by suggesting that highly unreliable scenarios with longer MTTF and MTTR (e.g. Fig. 5c) scenario are more sensitive to higher costs than moderately unreliable scenarios with shorter MTTR and MTTR (see, e.g. Fig. 5d). Thus, a bigger buffer capacity $(B C=6)$ is only more profitable than a smaller buffer capacity $(\mathrm{BC}=2)$ when very low costs (both $h$ and i) are present and when lower unreliability exists. Again, a reliable system is the exception, as a smaller buffer capacity is almost always more profitable in reliable scenarios (see Fig. $5 \mathrm{~g}$ : the blue surface $(\mathrm{BC}=2)$ is "above" the orange surface $(\mathrm{BC}=6)$ for most of the values of $h$ and $i)$. 
(a)

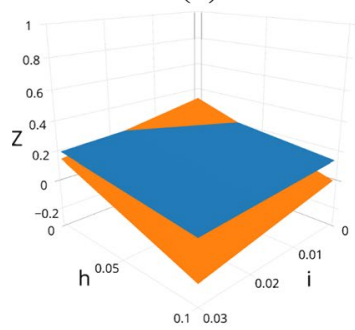

(d)

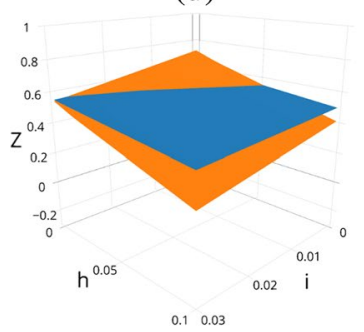

(b)

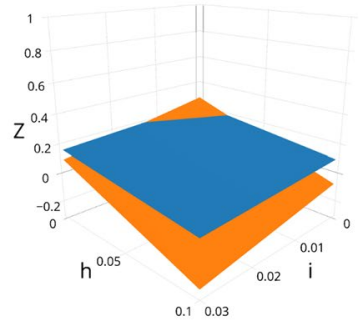

(e)

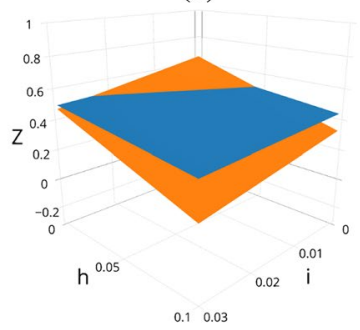

(g)

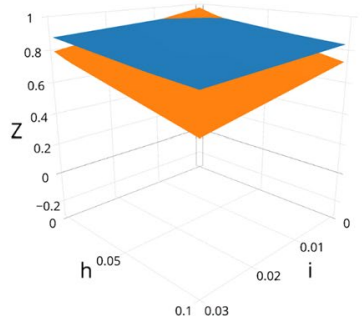

(c)

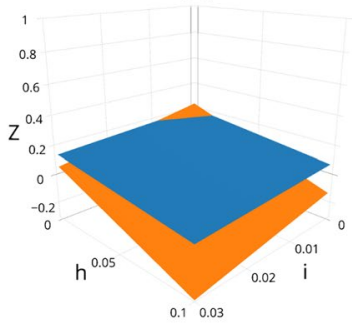

(f)

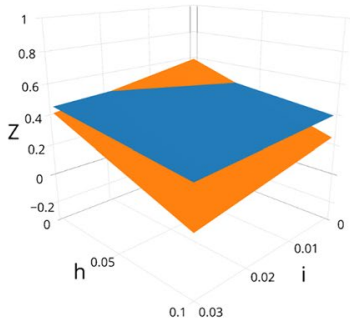

$\mathrm{BC}=2$

$\mathrm{BC}=6$

Fig. $5 Z$ function surface plots for $\mathrm{BC}=2$ (blue) and $\mathrm{BC}=6$ (orange) for different values of $h$ and $i$ considering experiments with $\mathrm{N}=5$ and a $\varepsilon=70.0 \%, \alpha=1, \mathbf{b} \varepsilon=70.0 \%, \alpha=2, \mathbf{c} \varepsilon=70.0 \%, \alpha=3$, d $\varepsilon=90.9 \%, \alpha=1$, e $\varepsilon=90.9 \%, \alpha=2, \mathbf{f} \varepsilon=90.9 \%, \alpha=3$, and $\mathbf{g} \varepsilon=100 \%, \alpha=0$ (colour figure online)

Note that results pertaining to merging lines with $\mathrm{N}=8$ and $\mathrm{N}=11$ are not shown as they are very similar to the ones presented in Fig. 5 and follow the same general pattern as in Fig. 4, i.e. the profit in longer lines is less penalised by inventory-related costs than for shorter lines. Furthermore, in order to reach the highest possible $Z$ values for Fig. 5, the best pattern for the corresponding $h$ values was considered. That is, for values lower than $h_{0}, \mathrm{BP}_{\operatorname{maxTR}}$ was used in the calculation of $Z$, whereas for values higher or equal to $h_{0}, \mathrm{BP}_{\operatorname{minABL}}$ was considered.

\section{Discussion}

An overall analysis of Sect. 5's results shows that the performance of buffer allocation patterns is highly dependent on the configuration of the system. The ascending unbalanced buffer allocation pattern (/) led to better TR performance with shorter, 
more unreliable lines; whereas the balanced pattern attained better TR performance when longer, more reliable lines were considered. These results suggest that different degrees of unreliability do influence which particular pattern is the best-performing, as question (1) of the study postulated.

Concerning ABL, the system's configuration did not influence the best-performing pattern. The ascending pattern was found to be the best pattern for all scenarios and the descending pattern was found to be the worst pattern for almost all scenarios.

Furthermore, the overall effect of buffer allocation patterns on TR was much higher in unreliable lines than in reliable lines, as the relative differences in TR among patterns (see Fig. 2) were much higher in unreliable scenarios than in reliable scenarios. However, despite the significant interaction effect between buffer allocation pattern and unreliability (BP: $\varepsilon$ in Table 2), the two reliability-related factors ( $\varepsilon$ and $\alpha$ ) were found to be the most significant factors for TR results, followed by the line's average buffer capacity.

In contrast, the effect of buffer allocation patterns on ABL was found to be much higher on reliable lines than on unreliable lines, showing a higher effect in shorter lines than in longer lines (see the comparison between Fig. 3a, c). Results from the Analysis of Variance test (Table 2) show that, overall, buffer capacity and buffer allocation pattern are the most important factors in the resulting ABL. Interaction effects such as buffer allocation pattern with reliability and length (BP:N:c) were also found to be statistically significant.

Thus, addressing question (2) of the study, results suggest that the relative impact of buffer allocation patterns for TR is low when compared with the impact of reliability, but is moderately high for ABL, since a good or bad pattern will significantly affect the average buffer content of a merging line. It was also found that all of the experimental factors considered in this study are statistically significant, confirming the results of previous studies regarding the effect of $\mathrm{N}, \mathrm{BC}, \varepsilon, \alpha$ and $\mathrm{BP}$ on TR (Conway et al. 1988; Hillier and So 1991; Tan 1998; Patti and Watson 2010; Shaaban et al. 2017).

Section 6 presents very interesting results on the impact of inventory holding costs and buffer capacity investment/maintenance costs on the profit of different merging line configurations. In this regard, shorter merging lines with higher levels of machine unreliability and longer MTTF and MTTR were found to be particularly sensitive to inventory-related costs since the values of both $h_{0}$ and $i_{0}$ were commonly close to zero. These results answer question (3) and confirm that merging line characteristics influence the performance of merging lines when considering inventoryrelated costs. Shorter, highly unreliable lines with long MTTF and MTTR tended to achieve a higher profit performance with a smaller buffer capacity (due to the tradeoff between additional buffer capacity costs and the additional TR generated by that capacity), and with buffer allocation patterns that reduced ABL (due to their comparatively high levels of average inventory content). Therefore, it can be reasonably concluded that increasing average buffer capacity per station from 2 to 6 in a merging line is more cost-effective for lines with a machine efficiency of $90.9 \%$, shorter MTTF and MTTR, and longer lines than it is for lines with $70 \%$ machine efficiency, longer MTTF and MTTR, and shorter lines. Despite these results, reliable merging lines were found to benefit the least by increasing buffer capacity, for the majority of 
inventory-related values, as only for near-to-zero inventory-related costs did a buffer capacity of 6 produce higher profit than a buffer capacity of 2 (see Fig. 5g).

Regarding the impact of costs on buffer allocation patterns, the results of the current study agree with those of Hillier (2013), who showed that buffer capacity should be significantly reduced and allocated towards the end of the line when inventory holding costs were high (e.g. $h=0.1$ ). Thus, investing in additional buffer capacity to increase throughput seems to be subject to the "Law of diminishing returns", according to the more general "Theory of performance frontiers" (Schmenner and Swink 1998), since investment in extra buffer capacity is seemingly only effective when both inventory holding costs and buffer capacity investment/maintenance costs are quite low (see, e.g. Fig. 5).

Many of the results from the current study confirm and extend previous results (see, e.g. Romero-Silva and Shaaban 2019) which found that inventory holding costs had a higher impact on the profit function of unreliable lines than on the profit of reliable lines, but some results contrast with previous research by finding that reliable lines were more affected by buffer capacity investment/maintenance costs than unreliable lines. These results also contribute new understanding by showing that the profit function of lines possessing machines with longer MTTF and MTTR was more highly impacted by both inventory holding costs and buffer capacity investment/maintenance costs than was the profit of lines having machines with shorter MTTF and MTTR.

These results suggest that managers, working in industries which produce goods through merging lines (e.g. automotive, electronics, window and door factories (Nahas et al. 2014)) with unreliable machines, stochastic processing times, and short line lengths, should consider unbalancing their buffers towards an ascending pattern. Furthermore, firms with high inventory-related costs, particularly those working in reliable machine industries, should be extremely careful when investing in additional buffer capacity, because the revenue gained through additional buffer capacity seldom covers the costs of obtaining that extra capacity. In practical terms, this means that industrial sectors with scarce inventory space (hence a high cost of expansion) and/or very high product value (hence higher inventory holding costs (Azzi et al. 2014)) should conduct serious cost-benefit analyses when considering buffer capacity expansion and line design (i.e. buffer allocation), particularly in reliable environments.

\subsection{Limitations of the study and future research}

All methodologies have limitations, so conclusions from this study are only applicable to the simulated experimental points and care should be taken when generalising the results. Despite this, these results provide value in supporting a better understanding of the impact of unreliability and inventory-related costs on the performance of uneven buffer allocation patterns. More experimental points need to be explored in future research extensions, particularly regarding the average buffer capacity per station, to better understand the benefits of buffer capacity and average inventory levels on the performance of merging lines under different costs profiles. 
The study's considerations on different machine efficiency values and various lengths of mean time to failure and to repair assumed a balanced allocation of these factors along the line, i.e. balanced unreliability. However, since it has been suggested that unreliability patterns have a significant effect on the performance of single serial lines (Hudson et al. 2015), further research is needed to understand the influence of unreliability allocation on the performance of merging lines.

\section{Conclusions}

This paper studied the effect of unbalancing buffer capacity with different levels of unreliability, various MTTF and MTTR lengths, and varying inventory-related costs through the simulation of merging lines with different number of stations and average buffer sizes. Experimental results suggest that shorter, more unreliable lines have higher TR with an ascending buffer allocation; whereas longer, more reliable lines have higher TR with a balanced pattern. Moreover, shorter, highly unreliable merging lines with longer MTTF and MTTR were found to be highly penalised by inventory-related costs. In addition, when compared with unreliable settings, reliable merging lines were found to profit the least from buffer capacity investments, as only environments with very low investment/maintenance costs would benefit from increasing buffer capacity in reliable scenarios.

Open Access This article is licensed under a Creative Commons Attribution 4.0 International License, which permits use, sharing, adaptation, distribution and reproduction in any medium or format, as long as you give appropriate credit to the original author(s) and the source, provide a link to the Creative Commons licence, and indicate if changes were made. The images or other third party material in this article are included in the article's Creative Commons licence, unless indicated otherwise in a credit line to the material. If material is not included in the article's Creative Commons licence and your intended use is not permitted by statutory regulation or exceeds the permitted use, you will need to obtain permission directly from the copyright holder. To view a copy of this licence, visit http://creativecommons.org/ licenses/by/4.0/.

\section{Appendix}

See Tables 3, 4, 5, 6 and 7. 
Table 3 Capacities for each buffer in different experimental configurations

\begin{tabular}{|c|c|c|c|c|c|c|c|c|c|c|c|}
\hline \multirow[t]{2}{*}{$\mathrm{n}$} & \multirow[t]{2}{*}{ Buffer } & \multicolumn{5}{|c|}{$\mathrm{BC}=2$} & \multicolumn{5}{|c|}{$\mathrm{BC}=6$} \\
\hline & & - & I & 1 & $\mathrm{~V}$ & $\Lambda$ & - & l & 1 & V & $\Lambda$ \\
\hline \multirow[t]{5}{*}{5} & $\mathrm{~B} 1 \mathrm{~A}$ or $\mathrm{B} 1 \mathrm{~B}$ & 2 & 1 & 5 & 4 & 1 & 6 & 3 & 15 & 12 & 3 \\
\hline & $\mathrm{B} 2 \mathrm{~A}$ or $\mathrm{B} 2 \mathrm{~B}$ & 2 & 1 & 1 & 1 & 2 & 6 & 3 & 3 & 3 & 6 \\
\hline & $\mathrm{B} 3 \mathrm{~A}$ or $\mathrm{B} 3 \mathrm{~B}$ & 2 & 1 & 1 & 1 & 4 & 6 & 3 & 3 & 3 & 12 \\
\hline & $\mathrm{B} 4 \mathrm{~A}$ or $\mathrm{B} 4 \mathrm{~B}$ & 2 & 5 & 1 & 2 & 1 & 6 & 15 & 3 & 6 & 3 \\
\hline & $\mathrm{F} 1$ or $\mathrm{F} 2$ & 2 & 2 & 2 & 2 & 2 & 6 & 6 & 6 & 6 & 6 \\
\hline \multirow[t]{8}{*}{8} & $\mathrm{~B} 1 \mathrm{~A}$ or $\mathrm{B} 1 \mathrm{~B}$ & 2 & 1 & 8 & 4 & 1 & 6 & 3 & 24 & 12 & 3 \\
\hline & $\mathrm{B} 2 \mathrm{~A}$ or $\mathrm{B} 2 \mathrm{~B}$ & 2 & 1 & 1 & 2 & 2 & 6 & 3 & 3 & 6 & 6 \\
\hline & $\mathrm{B} 3 \mathrm{~A}$ or $\mathrm{B} 3 \mathrm{~B}$ & 2 & 1 & 1 & 1 & 2 & 6 & 3 & 3 & 3 & 6 \\
\hline & $\mathrm{B} 4 \mathrm{~A}$ or $\mathrm{B} 4 \mathrm{~B}$ & 2 & 1 & 1 & 1 & 4 & 6 & 3 & 3 & 3 & 12 \\
\hline & $\mathrm{B} 5 \mathrm{~A}$ or $\mathrm{B} 5 \mathrm{~B}$ & 2 & 1 & 1 & 1 & 2 & 6 & 3 & 3 & 3 & 6 \\
\hline & $\mathrm{B} 6 \mathrm{~A}$ or $\mathrm{B} 6 \mathrm{~B}$ & 2 & 1 & 1 & 1 & 2 & 6 & 3 & 3 & 3 & 6 \\
\hline & $\mathrm{B} 7 \mathrm{~A}$ or $\mathrm{B} 7 \mathrm{~B}$ & 2 & 8 & 1 & 4 & 1 & 6 & 24 & 3 & 12 & 3 \\
\hline & $\mathrm{F} 1$ or $\mathrm{F} 2$ & 2 & 2 & 2 & 2 & 2 & 6 & 6 & 6 & 6 & 6 \\
\hline \multirow[t]{11}{*}{11} & $\mathrm{~B} 1 \mathrm{~A}$ or $\mathrm{B} 1 \mathrm{~B}$ & 2 & 1 & 8 & 4 & 1 & 6 & 3 & 24 & 12 & 3 \\
\hline & $\mathrm{B} 2 \mathrm{~A}$ or $\mathrm{B} 2 \mathrm{~B}$ & 2 & 1 & 4 & 2 & 1 & 6 & 3 & 12 & 6 & 3 \\
\hline & $\mathrm{B} 3 \mathrm{~A}$ or $\mathrm{B} 3 \mathrm{~B}$ & 2 & 1 & 1 & 2 & 2 & 6 & 3 & 3 & 6 & 6 \\
\hline & $\mathrm{B} 4 \mathrm{~A}$ or $\mathrm{B} 4 \mathrm{~B}$ & 2 & 1 & 1 & 1 & 2 & 6 & 3 & 3 & 3 & 6 \\
\hline & B5A or B5B & 2 & 1 & 1 & 1 & 4 & 6 & 3 & 3 & 3 & 12 \\
\hline & $\mathrm{B} 6 \mathrm{~A}$ or $\mathrm{B} 6 \mathrm{~B}$ & 2 & 1 & 1 & 1 & 4 & 6 & 3 & 3 & 3 & 12 \\
\hline & B7A or B7B & 2 & 1 & 1 & 1 & 2 & 6 & 3 & 3 & 3 & 6 \\
\hline & $\mathrm{B} 8 \mathrm{~A}$ or $\mathrm{B} 8 \mathrm{~B}$ & 2 & 1 & 1 & 2 & 2 & 6 & 3 & 3 & 6 & 6 \\
\hline & B9A or B9B & 2 & 4 & 1 & 2 & 1 & 6 & 12 & 3 & 6 & 3 \\
\hline & $\mathrm{B} 10 \mathrm{~A}$ or $\mathrm{B} 10 \mathrm{~B}$ & 2 & 8 & 1 & 4 & 1 & 6 & 24 & 3 & 12 & 3 \\
\hline & $\mathrm{F} 1$ or $\mathrm{F} 2$ & 2 & 2 & 2 & 2 & 2 & 6 & 6 & 6 & 6 & 6 \\
\hline
\end{tabular}




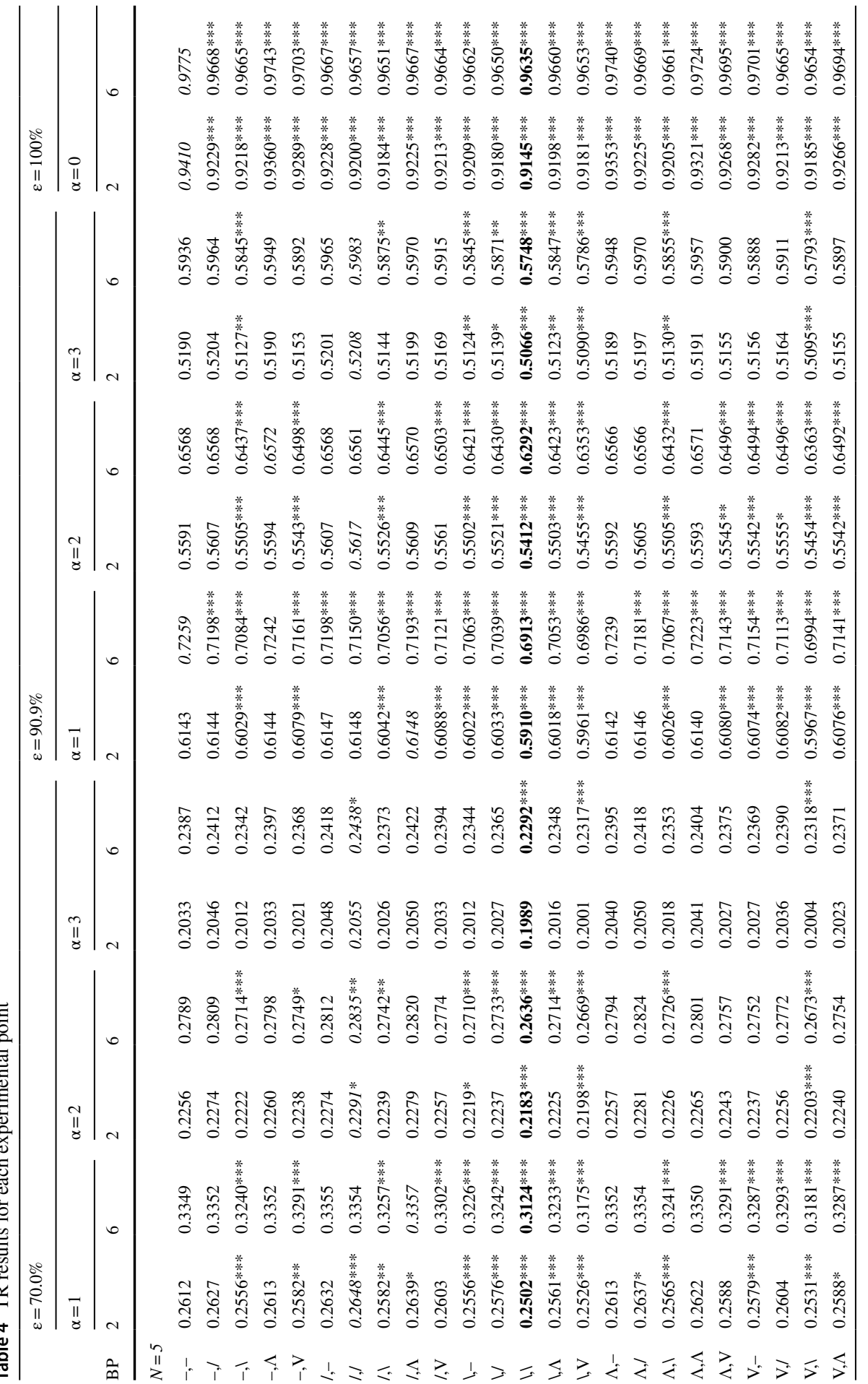




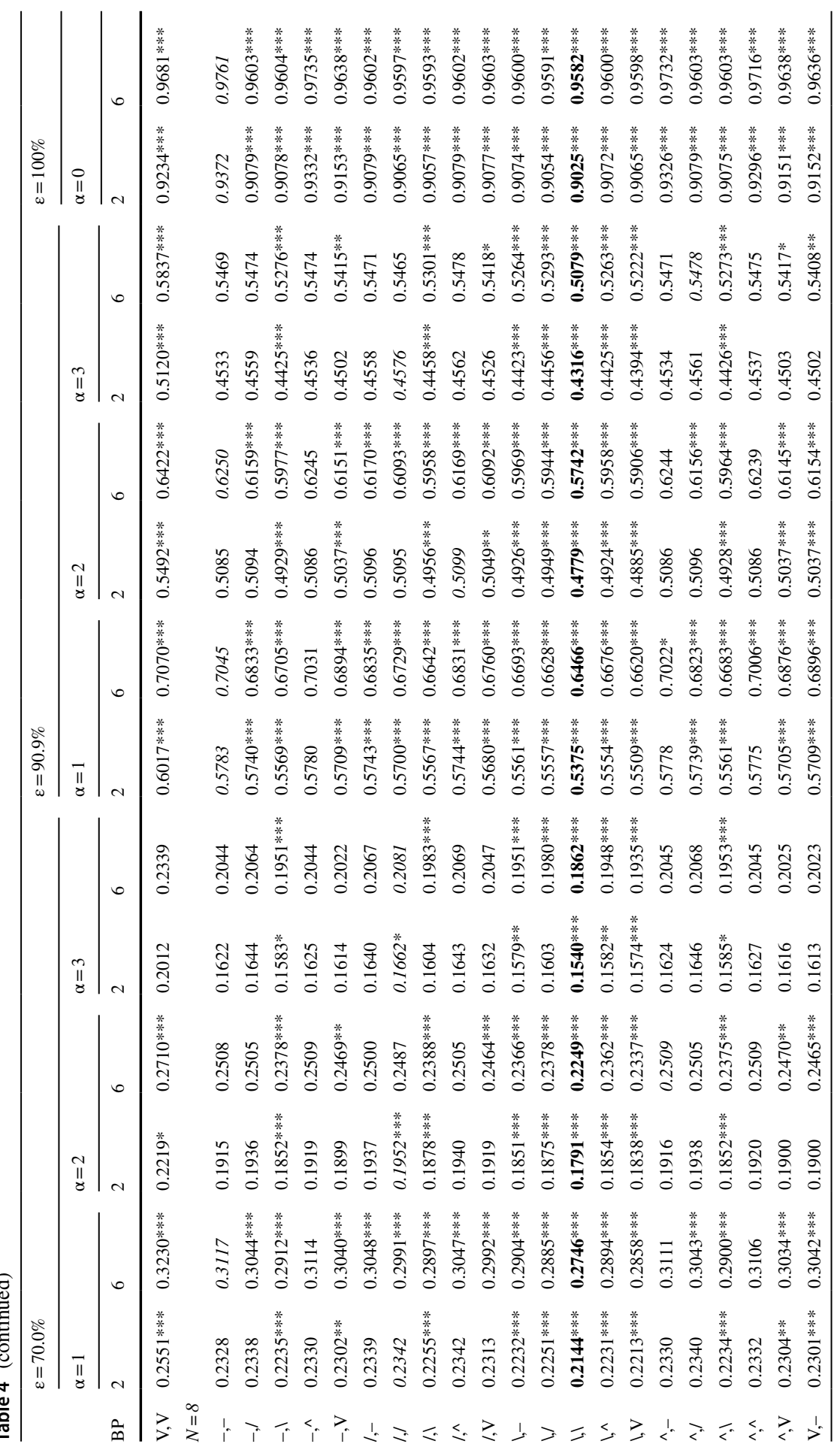




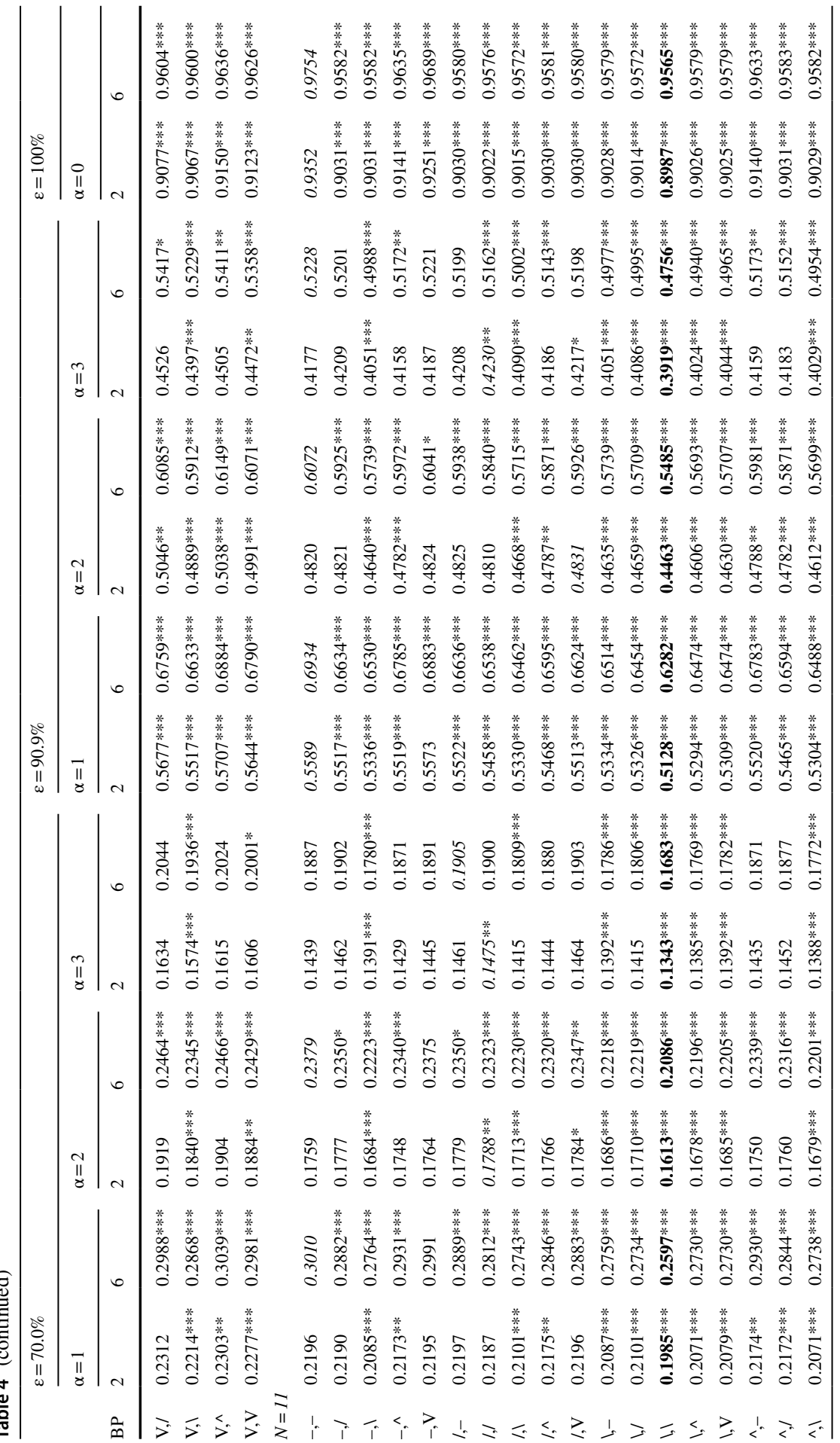




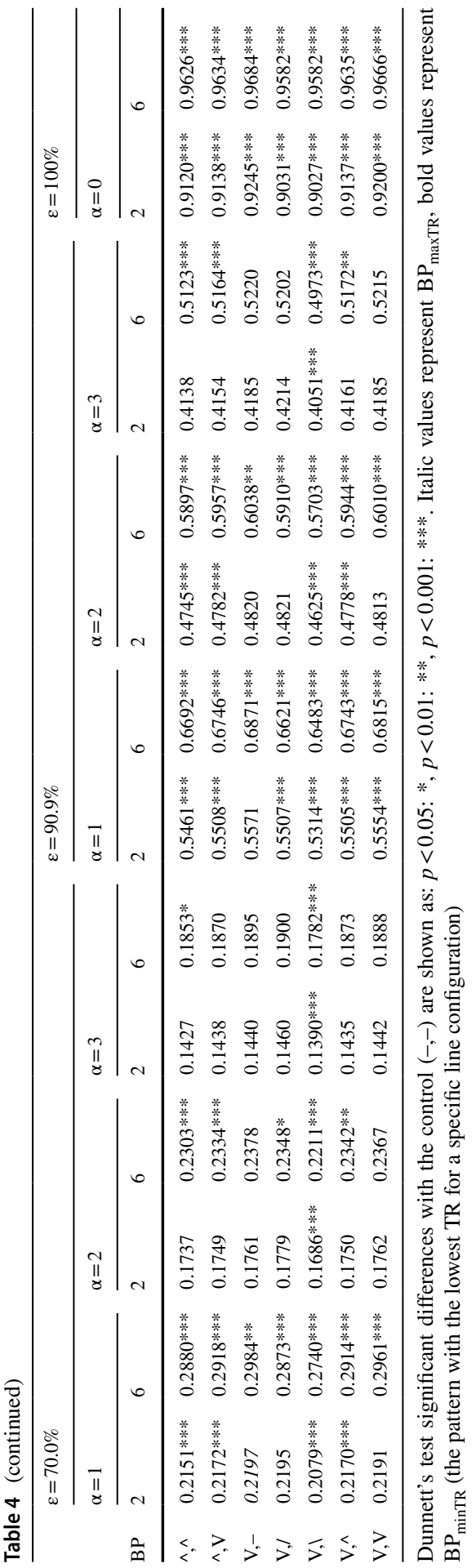


Table 5 TR Tukey's test groups per experimental point

\begin{tabular}{|c|c|c|c|c|c|c|c|c|c|c|c|c|c|c|}
\hline \multirow[t]{3}{*}{$\mathrm{BP}$} & \multicolumn{6}{|c|}{$\varepsilon=70.0 \%$} & \multicolumn{6}{|c|}{$\varepsilon=90.9 \%$} & \multirow{2}{*}{\multicolumn{2}{|c|}{$\begin{array}{l}\varepsilon=100 \% \\
\alpha=0\end{array}$}} \\
\hline & \multicolumn{2}{|l|}{$\alpha=1$} & \multicolumn{2}{|l|}{$\alpha=2$} & \multicolumn{2}{|l|}{$\alpha=3$} & \multicolumn{2}{|c|}{$\alpha=1$} & \multicolumn{2}{|l|}{$\alpha=2$} & \multicolumn{2}{|l|}{$\alpha=3$} & & \\
\hline & 2 & 6 & 2 & 6 & 2 & 6 & 2 & 6 & 2 & 6 & 2 & 6 & 2 & 6 \\
\hline \multicolumn{15}{|c|}{$N=5$} \\
\hline,-- & bcde & $\mathrm{a}$ & abcdef & abcdef & $a b$ & abcde & $\mathrm{a}$ & $\mathrm{a}$ & $a b$ & $\mathrm{a}$ & abcde & abcdef & $\mathrm{a}$ & $\mathrm{a}$ \\
\hline,$- l$ & abcd & a & abcd & $a b c$ & $\mathrm{a}$ & $a b c$ & $\mathrm{a}$ & $\mathrm{cd}$ & $\mathrm{a}$ & $\mathrm{a}$ & $a b$ & $a b c$ & $\mathrm{i}$ & gh \\
\hline,- 1 & hij & d & fghi & ijk & $a b$ & efg & $\mathrm{c}$ & $\mathrm{i}$ & def & $\mathrm{c}$ & efghi & hij & $\mathrm{j}$ & ghi \\
\hline,$-^{\wedge}$ & bcde & $\mathrm{a}$ & abcdef & abcde & $a b$ & abcde & $\mathrm{a}$ & $a b$ & $\mathrm{ab}$ & $\mathrm{a}$ & abcde & abcde & $\mathrm{b}$ & $\mathrm{b}$ \\
\hline,$- \mathrm{V}$ & fgh & $\mathrm{bc}$ & cdefgh & fghij & $a b$ & bcdef & $\mathrm{b}$ & ef & cde & $\mathrm{b}$ & abcdefg & efgh & e & $\mathrm{d}$ \\
\hline I,- & $a b c$ & a & abcd & $a b c$ & $\mathrm{a}$ & $a b$ & $\mathrm{a}$ & $\mathrm{cd}$ & $\mathrm{a}$ & $\mathrm{a}$ & $a b c$ & $\mathrm{ab}$ & $\mathrm{i}$ & $\mathrm{gh}$ \\
\hline I,I & $\mathrm{a}$ & $\mathrm{a}$ & $\mathrm{a}$ & $\mathrm{a}$ & $\mathrm{a}$ & $\mathrm{a}$ & $\mathrm{a}$ & f & $\mathrm{a}$ & a & $\mathrm{a}$ & $\mathrm{a}$ & $\mathrm{m}$ & $\mathrm{kl}$ \\
\hline$/, 1$ & fgh & $\mathrm{cd}$ & cdefgh & ghij & $a b$ & bcdef & $\mathrm{c}$ & ijk & cdef & $\mathrm{c}$ & bcdefgh & fgh & no & $\mathrm{m}$ \\
\hline$I^{\wedge}$ & $\mathrm{ab}$ & $\mathrm{a}$ & $a b c$ & $a b$ & $\mathrm{a}$ & $\mathrm{ab}$ & $\mathrm{a}$ & $\mathrm{d}$ & $\mathrm{a}$ & $\mathrm{a}$ & $a b c$ & $a b$ & $\mathrm{i}$ & gh \\
\hline$/, \mathrm{V}$ & def & $\mathrm{b}$ & abcdef & bcdefg & $a b$ & abcde & $\mathrm{b}$ & gh & $\mathrm{bc}$ & $\mathrm{b}$ & abcdef & bcdefg & $\mathrm{k}$ & hij \\
\hline $1,-$ & hij & $\mathrm{d}$ & fghi & $\mathrm{jk}$ & $a b$ & defg & $\mathrm{c}$ & $\mathrm{ijk}$ & ef & $\mathrm{c}$ & fghi & hij & $\mathrm{kl}$ & $\mathrm{ijk}$ \\
\hline$\backslash, /$ & fghi & $\mathrm{d}$ & defgh & ghij & $a b$ & bcdef & $\mathrm{c}$ & $\mathrm{k}$ & cdef & $\mathrm{c}$ & cdefgh & gh & o & $\mathrm{m}$ \\
\hline$\backslash, 1$ & 1 & $\mathrm{f}$ & $\mathrm{i}$ & 1 & $\mathrm{~b}$ & $\mathrm{~g}$ & e & $\mathrm{m}$ & $\mathrm{h}$ & $\mathrm{e}$ & $\mathrm{i}$ & $\mathrm{k}$ & $\mathrm{p}$ & $\mathrm{n}$ \\
\hline$\backslash, \wedge$ & ghi & $\mathrm{d}$ & efghi & ijk & $a b$ & defg & $\mathrm{c}$ & $\mathrm{jk}$ & def & $\mathrm{c}$ & fghi & hij & $\mathrm{m}$ & $\mathrm{jk}$ \\
\hline$\backslash, \mathrm{V}$ & $\mathrm{kl}$ & $\mathrm{e}$ & hi & $\mathrm{kl}$ & $a b$ & $\mathrm{fg}$ & $\mathrm{d}$ & 1 & $\mathrm{~g}$ & $\mathrm{~d}$ & hi & $\mathrm{jk}$ & no & $\operatorname{lm}$ \\
\hline$\stackrel{\wedge}{,-}$ & bcde & $\mathrm{a}$ & abcdef & abcdef & $a b$ & abcde & $\mathrm{a}$ & $a b$ & $a b$ & $\mathrm{a}$ & abcde & abcde & $\mathrm{c}$ & $\mathrm{b}$ \\
\hline$\wedge, /$ & $a b$ & $\mathrm{a}$ & $a b$ & $\mathrm{a}$ & $\mathrm{a}$ & $a b$ & a & de & $\mathrm{a}$ & a & $a b c$ & $a b$ & $\mathrm{i}$ & $\mathrm{g}$ \\
\hline$\wedge, 1$ & ghi & d & efgh & hij & $a b$ & cdefg & $\mathrm{c}$ & ijk & def & $\mathrm{c}$ & defgh & ghi & 1 & $\mathrm{ijk}$ \\
\hline$\wedge, \wedge$ & abcd & $\mathrm{a}$ & abcde & abcd & $a b$ & abcd & $\mathrm{a}$ & $\mathrm{bc}$ & $a b$ & $\mathrm{a}$ & abcd & abcd & $\mathrm{d}$ & $\mathrm{c}$ \\
\hline$\stackrel{\wedge}{ }, \mathrm{V}$ & efg & $\mathrm{bc}$ & bcdefg & defghi & $a b$ & bcdef & $\mathrm{b}$ & fg & $\mathrm{cd}$ & $\mathrm{b}$ & abcdefg & cdefgh & $\mathrm{g}$ & $\mathrm{e}$ \\
\hline $\mathrm{V},-$ & fghi & $\mathrm{bc}$ & defgh & efghij & $a b$ & bcdef & $\mathrm{b}$ & ef & cde & $\mathrm{b}$ & abcdefg & efgh & $\mathrm{f}$ & $\mathrm{d}$ \\
\hline $\mathrm{V}, \mathrm{I}$ & cdef & $\mathrm{b}$ & abcdef & cdefgh & $a b$ & abcde & $\mathrm{b}$ & $\mathrm{h}$ & $\mathrm{bc}$ & $\mathrm{b}$ & abcdef & bcdefg & $\mathrm{k}$ & ghi \\
\hline $\mathrm{V}, \mathrm{I}$ & $\mathrm{jkl}$ & $\mathrm{e}$ & ghi & $\mathrm{kl}$ & $a b$ & fg & $\mathrm{d}$ & 1 & $\mathrm{~g}$ & $\mathrm{~d}$ & ghi & ijk & $\mathrm{n}$ & $\operatorname{lm}$ \\
\hline $\mathrm{V}, \wedge$ & efg & $\mathrm{bc}$ & bcdefgh & efghij & $a b$ & bcdef & $\mathrm{b}$ & fgh & cde & $\mathrm{b}$ & abcdefg & defgh & $\mathrm{g}$ & $\mathrm{e}$ \\
\hline $\mathrm{V}, \mathrm{V}$ & $\mathrm{ijk}$ & $\mathrm{d}$ & fghi & $\mathrm{jk}$ & $a b$ & efg & $\mathrm{c}$ & $\mathrm{ij}$ & fg & $\mathrm{c}$ & fghi & hij & $\mathrm{h}$ & $\mathrm{f}$ \\
\hline \multicolumn{15}{|c|}{$N=8$} \\
\hline,-- & $a b$ & $\mathrm{a}$ & bcde & $\mathrm{a}$ & abcde & $a b c$ & $\mathrm{a}$ & $\mathrm{a}$ & $a b$ & $\mathrm{a}$ & abcd & $a b c$ & $\mathrm{a}$ & $\mathrm{a}$ \\
\hline,$- /$ & $\mathrm{a}$ & $\mathrm{b}$ & $a b c$ & $\mathrm{ab}$ & $a b c$ & $a b$ & $\mathrm{~b}$ & $\mathrm{~d}$ & $\mathrm{a}$ & $\mathrm{b}$ & $a b$ & $\mathrm{a}$ & $\mathrm{g}$ & $\mathrm{f}$ \\
\hline,- 1 & ef & $\mathrm{d}$ & ghi & fg & defg & $\mathrm{f}$ & $\mathrm{g}$ & gh & $\mathrm{e}$ & $\mathrm{d}$ & gh & gh & gh & $\mathrm{f}$ \\
\hline,$-^{\wedge}$ & $a b$ & $\mathrm{a}$ & bcd & $\mathrm{a}$ & abcd & $a b c$ & $\mathrm{a}$ & $a b$ & $\mathrm{a}$ & $\mathrm{a}$ & abcd & $\mathrm{a}$ & $\mathrm{b}$ & $\mathrm{b}$ \\
\hline,$- \mathrm{V}$ & $\mathrm{c}$ & $\mathrm{b}$ & def & bcd & bcdefg & bcd & $\mathrm{c}$ & $\mathrm{c}$ & $\mathrm{c}$ & $\mathrm{b}$ & def & cde & e & $\mathrm{d}$ \\
\hline I,- & $\mathrm{a}$ & $\mathrm{b}$ & $a b$ & $a b c$ & $a b c$ & $a b$ & $\mathrm{~b}$ & $\mathrm{~d}$ & $\mathrm{a}$ & $\mathrm{b}$ & $a b c$ & $a b$ & $\mathrm{~g}$ & fg \\
\hline I,I & a & $\mathrm{c}$ & $\mathrm{a}$ & abcd & a & $\mathrm{a}$ & cde & $\mathrm{g}$ & $\mathrm{a}$ & $\mathrm{c}$ & $\mathrm{a}$ & abcd & $\mathrm{j}$ & hi \\
\hline I,I & de & $\mathrm{d}$ & fgh & $\mathrm{f}$ & cdefg & def & $\mathrm{g}$ & $\mathrm{j}$ & de & $\mathrm{d}$ & $\mathrm{fg}$ & g & $\mathrm{k}$ & $\mathrm{ij}$ \\
\hline$I^{\wedge} \wedge$ & $\mathrm{a}$ & $\mathrm{b}$ & $\mathrm{ab}$ & $\mathrm{ab}$ & $a b c$ & $\mathrm{ab}$ & $\mathrm{b}$ & $\mathrm{d}$ & $\mathrm{a}$ & $\mathrm{b}$ & $\mathrm{a}$ & $\mathrm{a}$ & $\mathrm{g}$ & $\mathrm{fg}$ \\
\hline$/, \mathrm{V}$ & $\mathrm{bc}$ & $\mathrm{c}$ & bcd & cde & $a b c$ & $a b c$ & de & $\mathrm{f}$ & $\mathrm{bc}$ & $\mathrm{c}$ & abcde & bcde & gh & f \\
\hline ।,- & ef & $\mathrm{d}$ & hi & fgh & fgh & $\mathrm{f}$ & $\mathrm{g}$ & hi & ef & $\mathrm{d}$ & gh & gh & hi & fgh \\
\hline$\backslash, /$ & $\mathrm{e}$ & def & fgh & fg & cdefg & def & $\mathrm{g}$ & $\mathrm{j}$ & $\mathrm{e}$ & de & fg & $\mathrm{g}$ & $\mathrm{k}$ & $\mathrm{j}$ \\
\hline 1,1 & $\mathrm{~g}$ & $\mathrm{~g}$ & $\mathrm{j}$ & i & $\mathrm{h}$ & $\mathrm{g}$ & i & $\mathrm{k}$ & $\mathrm{h}$ & $\mathrm{g}$ & $\mathrm{i}$ & i & 1 & $\mathrm{k}$ \\
\hline$\backslash, \wedge$ & ef & de & ghi & fgh & efgh & f & $\mathrm{g}$ & $\mathrm{i}$ & ef & $\mathrm{d}$ & gh & gh & $\mathrm{i}$ & fgh \\
\hline$\backslash, \mathrm{V}$ & $\mathrm{f}$ & $\mathrm{f}$ & i & $\mathrm{h}$ & fgh & $\mathrm{f}$ & $\mathrm{h}$ & $\mathrm{j}$ & $\mathrm{g}$ & $\mathrm{f}$ & $\mathrm{h}$ & $\mathrm{h}$ & $\mathrm{j}$ & gh \\
\hline
\end{tabular}


Table 5 (continued)

\begin{tabular}{|c|c|c|c|c|c|c|c|c|c|c|c|c|c|c|}
\hline \multirow[t]{3}{*}{$\mathrm{BP}$} & \multicolumn{6}{|c|}{$\varepsilon=70.0 \%$} & \multicolumn{6}{|c|}{$\varepsilon=90.9 \%$} & \multirow{2}{*}{\multicolumn{2}{|c|}{$\begin{array}{l}\varepsilon=100 \% \\
\alpha=0\end{array}$}} \\
\hline & \multicolumn{2}{|l|}{$\alpha=1$} & \multicolumn{2}{|l|}{$\alpha=2$} & \multicolumn{2}{|l|}{$\alpha=3$} & \multicolumn{2}{|l|}{$\alpha=1$} & \multicolumn{2}{|c|}{$\alpha=2$} & \multicolumn{2}{|l|}{$\alpha=3$} & & \\
\hline & 2 & 6 & 2 & 6 & 2 & 6 & 2 & 6 & 2 & 6 & 2 & 6 & 2 & 6 \\
\hline$\wedge,-$ & $\mathrm{ab}$ & $\mathrm{a}$ & bcde & $\mathrm{a}$ & abcd & $a b c$ & $\mathrm{a}$ & $a b$ & $\mathrm{a}$ & $\mathrm{a}$ & abcd & $a b$ & $\mathrm{c}$ & $\mathrm{b}$ \\
\hline$\wedge, /$ & $\mathrm{a}$ & $\mathrm{b}$ & $a b$ & $a b$ & $a b$ & $a b$ & $\mathrm{~b}$ & $\mathrm{~d}$ & $\mathrm{a}$ & $\mathrm{b}$ & $\mathrm{a}$ & $\mathrm{a}$ & gh & $\mathrm{f}$ \\
\hline$\wedge, 1$ & ef & d & ghi & $\mathrm{fg}$ & defg & ef & $\mathrm{g}$ & hi & $\mathrm{e}$ & d & gh & gh & ghi & $\mathrm{f}$ \\
\hline$\wedge, \wedge$ & $a b$ & $\mathrm{a}$ & abcd & $\mathrm{a}$ & $a b c$ & $a b c$ & a & $\mathrm{b}$ & a & a & abcd & $\mathrm{a}$ & $\mathrm{d}$ & c \\
\hline$\wedge, \mathrm{V}$ & $\mathrm{c}$ & $\mathrm{b}$ & def & bcd & bcdef & bcd & $\mathrm{cd}$ & $\mathrm{c}$ & $\mathrm{c}$ & $\mathrm{b}$ & cdef & bcde & e & $\mathrm{d}$ \\
\hline $\mathrm{V},-$ & $\mathrm{c}$ & $\mathrm{b}$ & def & $\mathrm{cd}$ & bcdefg & bcd & $\mathrm{c}$ & $\mathrm{c}$ & $\mathrm{c}$ & $\mathrm{b}$ & def & ef & e & d \\
\hline $\mathrm{V}, /$ & $\mathrm{bc}$ & $\mathrm{c}$ & bcd & de & $a b c$ & $a b c$ & e & $\mathrm{f}$ & $\mathrm{c}$ & $\mathrm{c}$ & abcde & bcde & gh & $\mathrm{f}$ \\
\hline $\mathrm{V}, \mathrm{I}$ & $\mathrm{f}$ & ef & $\mathrm{i}$ & gh & gh & f & $\mathrm{h}$ & $\mathrm{j}$ & $\mathrm{fg}$ & ef & $\mathrm{h}$ & $\mathrm{h}$ & $\mathrm{j}$ & fgh \\
\hline $\mathrm{V}, \wedge$ & $\mathrm{c}$ & $\mathrm{b}$ & cdef & $\mathrm{cd}$ & bcdefg & bcd & $\mathrm{c}$ & $\mathrm{c}$ & $\mathrm{c}$ & $\mathrm{b}$ & bcdef & def & $\mathrm{e}$ & $\mathrm{d}$ \\
\hline $\mathrm{V}, \mathrm{V}$ & $\mathrm{d}$ & $\mathrm{c}$ & efg & e & bcdefg & cde & f & e & $\mathrm{d}$ & $\mathrm{c}$ & efg & $\mathrm{f}$ & $\mathrm{f}$ & e \\
\hline \multicolumn{15}{|c|}{$N=11$} \\
\hline,-- & $\mathrm{a}$ & $\mathrm{a}$ & abcde & $\mathrm{a}$ & bcde & $a b$ & $\mathrm{a}$ & $\mathrm{a}$ & $\mathrm{a}$ & $\mathrm{a}$ & bcde & $\mathrm{a}$ & $\mathrm{a}$ & $\mathrm{a}$ \\
\hline,$- /$ & $\mathrm{abcd}$ & $\mathrm{f}$ & abcd & abcd & $a b c$ & $\mathrm{a}$ & $\mathrm{c}$ & $\mathrm{g}$ & $\mathrm{a}$ & fgh & $a b c$ & abcd & $\mathrm{g}$ & $\mathrm{g}$ \\
\hline,- 1 & $\mathrm{fg}$ & i & gh & $\mathrm{g}$ & $\mathrm{g}$ & $\mathrm{c}$ & $\mathrm{e}$ & $\mathrm{i}$ & efg & $\mathrm{k}$ & gh & $\mathrm{fg}$ & $\mathrm{gh}$ & $\mathrm{g}$ \\
\hline,$-^{\wedge}$ & $\mathrm{cd}$ & $\mathrm{d}$ & de & cde & cde & $a b$ & $\mathrm{c}$ & $\mathrm{d}$ & $\mathrm{bc}$ & de & $\mathrm{e}$ & bcde & $\mathrm{e}$ & $\mathrm{e}$ \\
\hline,$- \mathrm{V}$ & $a b$ & $a b$ & abcde & $\mathrm{ab}$ & abcde & $\mathrm{ab}$ & $a b$ & $\mathrm{~b}$ & $\mathrm{a}$ & $a b$ & abcde & $\mathrm{ab}$ & $\mathrm{b}$ & $\mathrm{b}$ \\
\hline I,- & $\mathrm{a}$ & ef & $a b c$ & abcd & abcd & $\mathrm{a}$ & $\mathrm{c}$ & $\mathrm{g}$ & $\mathrm{a}$ & $\mathrm{fg}$ & abcd & abcd & gh & $\mathrm{gh}$ \\
\hline I,I & abcd & $\mathrm{h}$ & $\mathrm{a}$ & def & $\mathrm{a}$ & $\mathrm{a}$ & $\mathrm{d}$ & $\mathrm{i}$ & $a b$ & $\mathrm{j}$ & $\mathrm{a}$ & cde & $\mathrm{j}$ & hi \\
\hline$/, 1$ & $\mathrm{f}$ & ijk & $\mathrm{fg}$ & $\mathrm{g}$ & efg & $\mathrm{c}$ & ef & $\operatorname{lm}$ & $\mathrm{e}$ & $\mathrm{kl}$ & $\mathrm{fg}$ & $\mathrm{f}$ & $\mathrm{k}$ & $\mathrm{ij}$ \\
\hline$I^{\wedge}$ & bcd & $\mathrm{g}$ & abcde & def & abcde & $a b$ & $\mathrm{~d}$ & $\mathrm{~h}$ & $\mathrm{bc}$ & $\mathrm{ij}$ & abcde & e & $\mathrm{gh}$ & $\mathrm{g}$ \\
\hline I,V & $\mathrm{a}$ & $\mathrm{f}$ & $\mathrm{a}$ & abcde & $\mathrm{ab}$ & $\mathrm{a}$ & $\mathrm{c}$ & $\mathrm{g}$ & $\mathrm{a}$ & fgh & $\mathrm{ab}$ & abcd & gh & gh \\
\hline I,- & $\mathrm{fg}$ & ij & gh & $\mathrm{g}$ & $\mathrm{fg}$ & $\mathrm{c}$ & $\mathrm{e}$ & ij & fgh & $\mathrm{k}$ & gh & $\mathrm{fg}$ & ghi & $\mathrm{gh}$ \\
\hline$\backslash, /$ & $\mathrm{f}$ & $\mathrm{jk}$ & $\mathrm{fg}$ & $\mathrm{g}$ & efg & $\mathrm{c}$ & efg & $\mathrm{m}$ & ef & $\mathrm{kl}$ & $\mathrm{g}$ & $\mathrm{f}$ & $\mathrm{k}$ & $\mathrm{j}$ \\
\hline 1,1 & $\mathrm{~h}$ & 1 & $\mathrm{i}$ & $\mathrm{h}$ & $\mathrm{h}$ & $\mathrm{d}$ & $\mathrm{i}$ & $\mathrm{n}$ & $\mathrm{i}$ & $\mathrm{m}$ & $\mathrm{i}$ & $\mathrm{h}$ & 1 & $\mathrm{k}$ \\
\hline$\backslash, \wedge$ & $\mathrm{g}$ & $\mathrm{k}$ & $\mathrm{h}$ & $\mathrm{g}$ & $\mathrm{g}$ & $\mathrm{c}$ & $\mathrm{h}$ & $\mathrm{klm}$ & $\mathrm{h}$ & 1 & $\mathrm{~h}$ & $\mathrm{~g}$ & hi & $\mathrm{gh}$ \\
\hline I,V & $\mathrm{g}$ & $\mathrm{k}$ & $\mathrm{gh}$ & $\mathrm{g}$ & $\mathrm{fg}$ & $\mathrm{c}$ & fgh & $\mathrm{klm}$ & fgh & $\mathrm{kl}$ & gh & $\mathrm{fg}$ & ij & $\mathrm{gh}$ \\
\hline$\wedge,-$ & $\mathrm{cd}$ & $\mathrm{d}$ & bcde & cde & bcde & $a b$ & $\mathrm{c}$ & $\mathrm{d}$ & $\mathrm{bc}$ & $\mathrm{cd}$ & de & bcde & $\mathrm{e}$ & $\mathrm{e}$ \\
\hline$\wedge$, & $\mathrm{cd}$ & $\mathrm{g}$ & abcde & ef & abcd & $a b$ & $\mathrm{~d}$ & $\mathrm{~h}$ & $\mathrm{bc}$ & $\mathrm{ij}$ & abcde & de & $\mathrm{g}$ & $\mathrm{g}$ \\
\hline$\wedge, 1$ & $\mathrm{~g}$ & $\mathrm{jk}$ & $\mathrm{h}$ & $\mathrm{g}$ & $\mathrm{g}$ & $\mathrm{c}$ & gh & $\mathrm{jk}$ & gh & 1 & $\mathrm{~h}$ & $\mathrm{fg}$ & gh & $\mathrm{g}$ \\
\hline$\wedge, \wedge$ & $\mathrm{e}$ & $\mathrm{f}$ & ef & $\mathrm{f}$ & def & $\mathrm{b}$ & $\mathrm{d}$ & $\mathrm{f}$ & $\mathrm{d}$ & hi & ef & $\mathrm{e}$ & $\mathrm{f}$ & $\mathrm{f}$ \\
\hline$\wedge, \mathrm{V}$ & $\mathrm{cd}$ & $\mathrm{d}$ & cde & cdef & bcde & $a b$ & $\mathrm{c}$ & e & $\mathrm{bc}$ & def & $\mathrm{e}$ & cde & $\mathrm{e}$ & $\mathrm{e}$ \\
\hline $\mathrm{V},-$ & $\mathrm{a}$ & $\mathrm{bc}$ & abcde & $\mathrm{a}$ & abcde & $\mathrm{a}$ & $a b$ & $\mathrm{~b}$ & $\mathrm{a}$ & $\mathrm{b}$ & abcde & $\mathrm{ab}$ & $\mathrm{c}$ & $\mathrm{c}$ \\
\hline $\mathrm{V}, /$ & $a b$ & $\mathrm{f}$ & $a b$ & abcde & abcd & $\mathrm{a}$ & $\mathrm{c}$ & $\mathrm{g}$ & $\mathrm{a}$ & gh & $a b$ & abcd & $\mathrm{g}$ & $\mathrm{g}$ \\
\hline $\mathrm{V}, \mathrm{I}$ & $\mathrm{g}$ & $\mathrm{ijk}$ & $\mathrm{gh}$ & $\mathrm{g}$ & $\mathrm{g}$ & $\mathrm{c}$ & efgh & $\mathrm{kl}$ & gh & 1 & gh & $\mathrm{fg}$ & hi & $\mathrm{g}$ \\
\hline $\mathrm{V},^{\wedge}$ & $\mathrm{de}$ & $\mathrm{de}$ & cde & bcde & bcde & $a b$ & $\mathrm{c}$ & $\mathrm{e}$ & $\mathrm{c}$ & ef & cde & bcde & $\mathrm{e}$ & e \\
\hline $\mathrm{V}, \mathrm{V}$ & $a b c$ & $\mathrm{c}$ & abcde & $a b c$ & abcde & $a b$ & $\mathrm{~b}$ & $\mathrm{c}$ & $a b$ & $\mathrm{bc}$ & abcde & $a b c$ & $\mathrm{~d}$ & $\mathrm{~d}$ \\
\hline
\end{tabular}




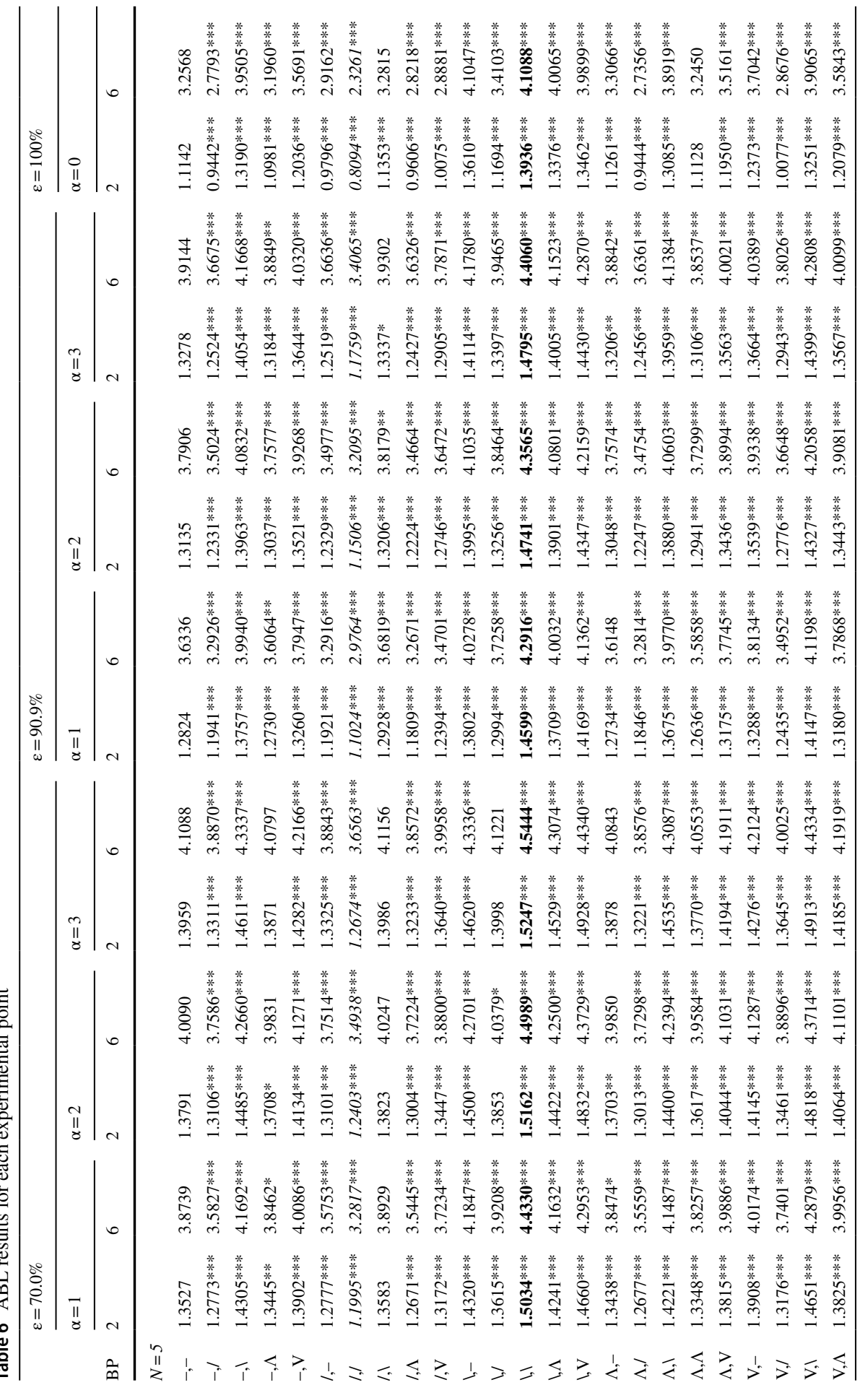




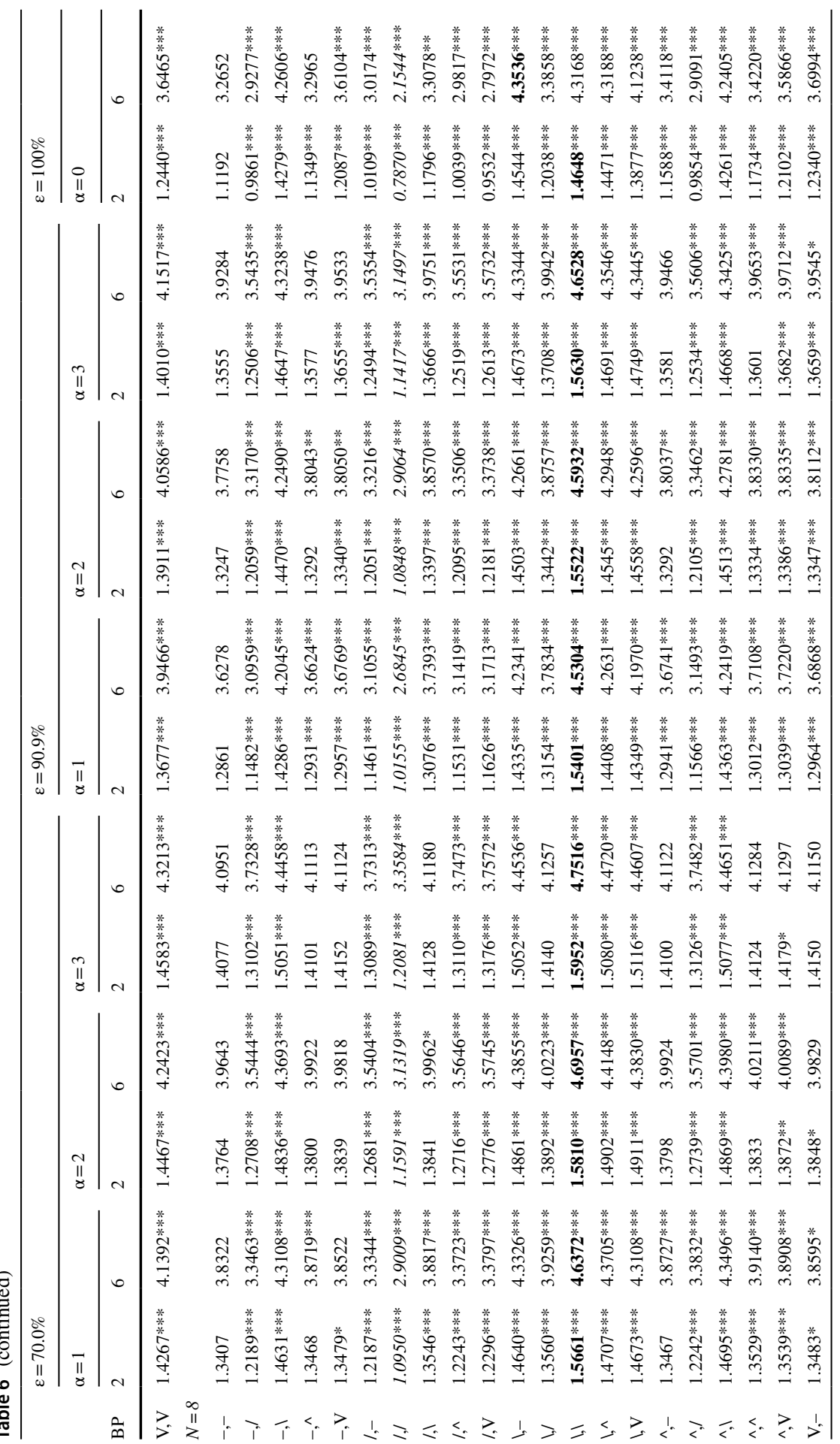




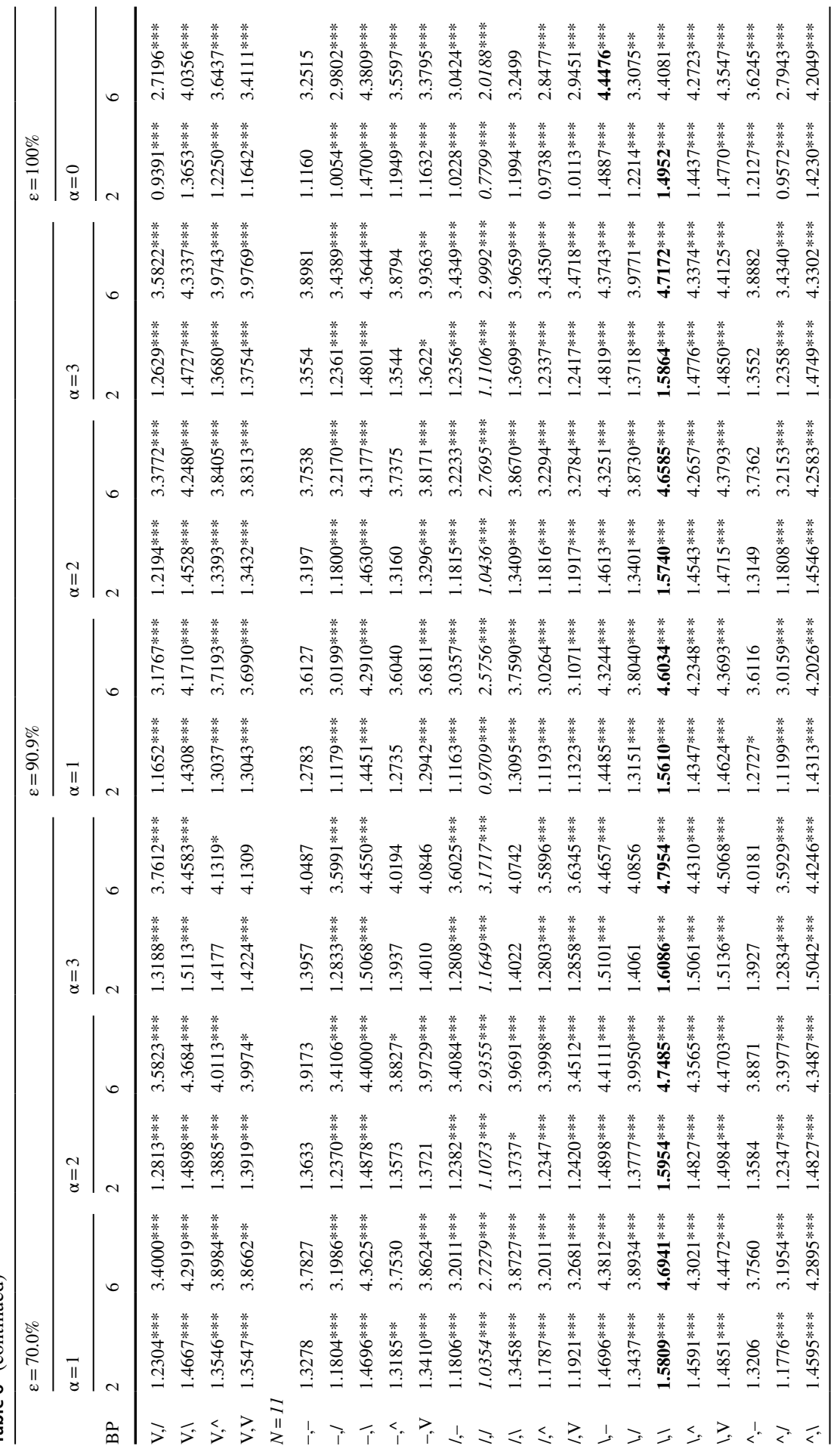




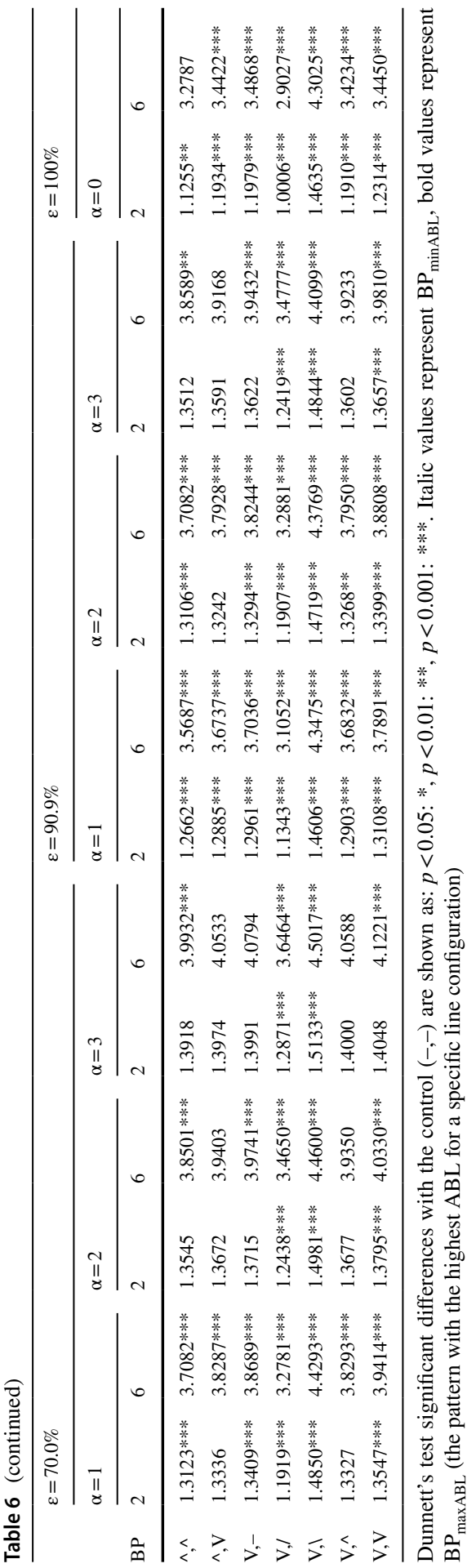


Table 7 ABL Tukey's test groups per experimental point

\begin{tabular}{|c|c|c|c|c|c|c|c|c|c|c|c|c|c|}
\hline \multirow[b]{3}{*}{ BP } & \multicolumn{6}{|c|}{$\varepsilon=70.0 \%$} & \multicolumn{6}{|c|}{$\varepsilon=90.9 \%$} & \multirow{2}{*}{$\begin{array}{l}\varepsilon=100 \% \\
\alpha=0\end{array}$} \\
\hline & $\alpha=$ & & $\alpha=$ & & $\alpha=$ & & $\alpha=$ & & & & $\alpha=$ & & \\
\hline & 2 & 6 & 2 & 6 & 2 & 6 & 2 & 6 & 2 & 6 & 2 & 6 & 6 \\
\hline
\end{tabular}

$N=5$

$\begin{array}{llllllllllllllll}-,- & \mathrm{j} & \mathrm{gh} & \mathrm{gh} & \text { ef } & \text { ef } & \text { ef } & \mathrm{j} & \mathrm{j} & \mathrm{i} & \mathrm{i} & \mathrm{i} & \mathrm{i} & \mathrm{o} & \mathrm{k}\end{array}$

$\begin{array}{lllllllllllllllll}-, / & \mathrm{n} & \mathrm{k} & \mathrm{k} & \mathrm{i} & \mathrm{i} & \mathrm{i} & \mathrm{n} & \mathrm{n} & \mathrm{m} & \mathrm{m} & \mathrm{m} & \mathrm{m} & \mathrm{t} & \mathrm{p}\end{array}$

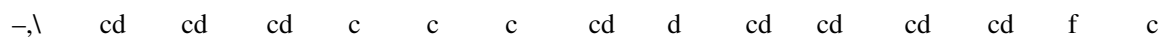

$\begin{array}{rllllllllllllllll}-, \wedge & k & \text { hi } & \text { hi } & \text { fg } & \text { fg } & \text { fg } & k & k l & j & j & \text { j } & \text { j } & \text { p } & 1\end{array}$

$\begin{array}{llllllllllllllllll}-, V & f g & e & \text { ef } & d & d & d & f & f g & f & e & f & \text { ef } & j & g\end{array}$

$\begin{array}{lllllllllllllllll}l,- & \mathrm{n} & \mathrm{k} & \mathrm{kl} & \mathrm{ij} & \mathrm{i} & \mathrm{i} & \mathrm{n} & \mathrm{n} & \mathrm{m} & \mathrm{m} & \mathrm{m} & \mathrm{mn} & \mathrm{r} & \mathrm{m}\end{array}$

$\begin{array}{lllllllllllllll}/, / & \mathrm{p} & \mathrm{m} & \mathrm{n} & \mathrm{k} & \mathrm{j} & \mathrm{j} & \mathrm{p} & \mathrm{o} & \mathrm{o} & \mathrm{o} & \mathrm{o} & \mathrm{p} & \mathrm{u} & \mathrm{r}\end{array}$

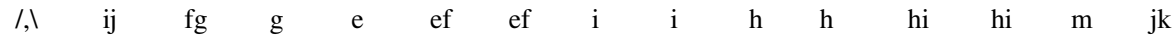

$\begin{array}{lllllllllllllllll}\wedge & \wedge & \mathrm{o} & \mathrm{l} & \mathrm{m} & \mathrm{j} & \mathrm{i} & \mathrm{i} & \mathrm{o} & \mathrm{n} & \mathrm{n} & \mathrm{n} & \mathrm{n} & \mathrm{o} & \mathrm{s} & \mathrm{o}\end{array}$

$\begin{array}{lllllllllllllllll}\text { /,V } & \mathrm{m} & \mathrm{j} & \mathrm{j} & \mathrm{h} & \mathrm{h} & \mathrm{h} & \mathrm{m} & \mathrm{m} & 1 & 1 & 1 & 1 & \mathrm{q} & \mathrm{mn}\end{array}$

$\begin{array}{llllllllllllllll}1,- & \mathrm{c} & \mathrm{c} & \mathrm{c} & \mathrm{c} & \mathrm{c} & \mathrm{c} & \mathrm{c} & \mathrm{c} & \mathrm{c} & \mathrm{c} & \mathrm{c} & \mathrm{c} & \mathrm{b} & \mathrm{a}\end{array}$

$\begin{array}{lllllllllllllllllllllll}l, / & \mathrm{i} & \mathrm{f} & \mathrm{g} & \mathrm{e} & \mathrm{e} & \mathrm{e} & \mathrm{h} & \mathrm{h} & \mathrm{h} & \mathrm{g} & \mathrm{h} & \mathrm{h} & \mathrm{l} & \mathrm{i}\end{array}$

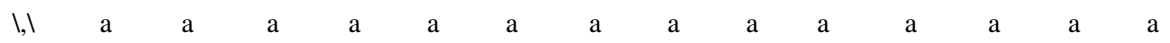

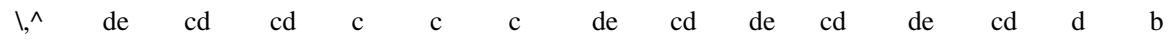

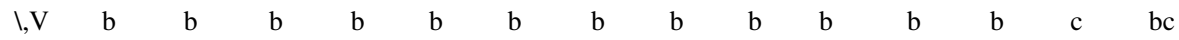

$\begin{array}{llllllllllllllllll}\wedge,- & k & \text { hi } & \text { hi } & \text { fg } & \text { efg } & \text { efg } & k & j k & j & j & j & j & n & j\end{array}$

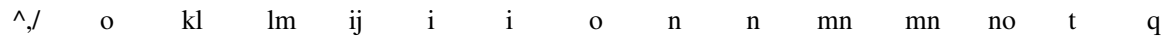

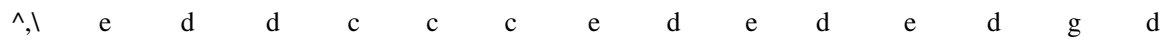

$\wedge, \wedge \quad 1 \quad$ i $\quad \begin{array}{lllllllllllllllll}\wedge & \mathrm{i} & \mathrm{g} & \mathrm{g} & \mathrm{g} & \mathrm{l} & \mathrm{l} & \mathrm{k} & \mathrm{k} & \mathrm{k} & \mathrm{k} & \mathrm{o} & \mathrm{k}\end{array}$

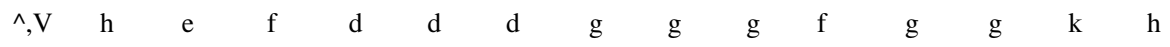

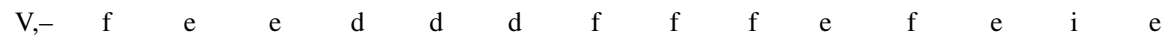

$\begin{array}{lllllllllllllllll}\mathrm{V}, / & \mathrm{m} & \mathrm{j} & \mathrm{j} & \mathrm{h} & \mathrm{h} & \mathrm{h} & \mathrm{m} & \mathrm{m} & 1 & 1 & 1 & 1 & \mathrm{q} & \mathrm{n}\end{array}$

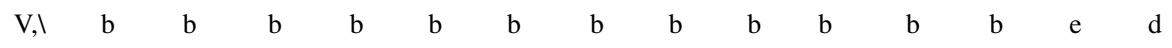

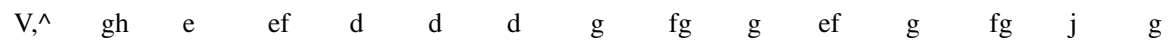

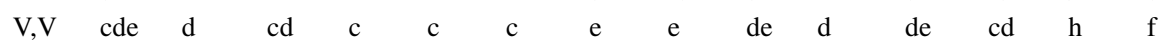

$N=8$

$\begin{array}{ccccccccccccccccc}-,- & \text { e } & \text { k } & \text { e } & \text { f } & \text { d } & \text { c } & \text { j } & 1 & \text { g } & \text { j } & \text { h } & \text { e } & \text { m } & \text { i }\end{array}$

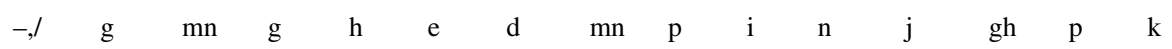

$\begin{array}{lllllllllllllll}-, l & b & d e & b & c & b & b & d & d & c & c d & d & b & d & b\end{array}$

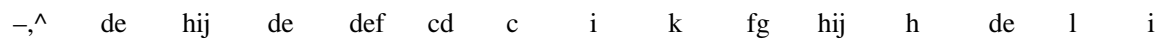

,$- \mathrm{V}$ cde jk cde ef cd c hi jk ef ghi fg de $\mathrm{i}$ fg

$\begin{array}{lllllllllllllllllllll}\text { /,- } & \mathrm{g} & \mathrm{n} & \mathrm{g} & \mathrm{h} & \mathrm{e} & \mathrm{d} & \mathrm{n} & \mathrm{p} & \mathrm{i} & \mathrm{mn} & \mathrm{j} & \mathrm{h} & \mathrm{n} & \mathrm{j}\end{array}$

$\begin{array}{lllllllllllllll}I, / & \mathrm{h} & \mathrm{o} & \mathrm{h} & \mathrm{i} & \mathrm{f} & \mathrm{e} & \mathrm{o} & \mathrm{q} & \mathrm{j} & \mathrm{o} & \mathrm{k} & \mathrm{i} & \mathrm{s} & \mathrm{n}\end{array}$

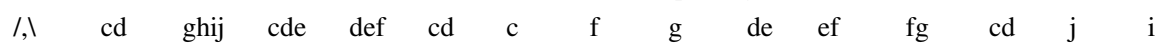

$\begin{array}{lllllllllllllllllll}\text {, } & \text { fg } & \operatorname{lm} & \text { fg } & \mathrm{gh} & \mathrm{e} & \mathrm{d} & \operatorname{lm} & \mathrm{o} & \mathrm{i} & \mathrm{klm} & \mathrm{j} & \mathrm{fgh} & \mathrm{o} & \mathrm{j}\end{array}$

$\begin{array}{llllllllllllllll}l, \mathrm{~V} & \mathrm{f} & \mathrm{l} & \mathrm{fg} & \mathrm{gh} & \mathrm{e} & \mathrm{d} & \mathrm{k} & \mathrm{mn} & \mathrm{h} & \mathrm{kl} & \mathrm{i} & \mathrm{fg} & \mathrm{q} & 1\end{array}$

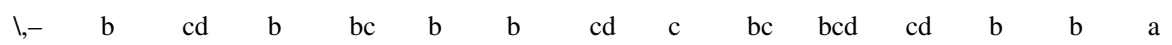

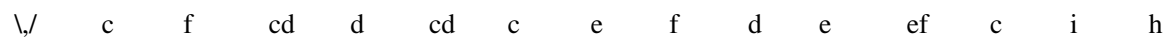

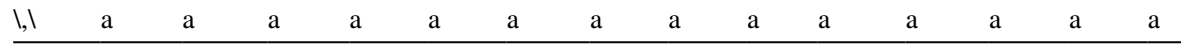


Table 7 (continued)

\begin{tabular}{|c|c|c|c|c|c|c|c|c|c|c|c|c|c|c|}
\hline \multirow[b]{3}{*}{ BP } & \multicolumn{6}{|c|}{$\varepsilon=70.0 \%$} & \multicolumn{6}{|c|}{$\varepsilon=90.9 \%$} & \multirow{2}{*}{\multicolumn{2}{|c|}{$\begin{array}{l}\varepsilon=100 \% \\
\alpha=0\end{array}$}} \\
\hline & \multicolumn{2}{|c|}{$\alpha=1$} & \multicolumn{2}{|c|}{$\alpha=2$} & \multicolumn{2}{|c|}{$\alpha=3$} & \multicolumn{2}{|c|}{$\alpha=1$} & \multicolumn{2}{|c|}{$\alpha=2$} & \multicolumn{2}{|c|}{$\alpha=3$} & & \\
\hline & 2 & 6 & 2 & 6 & 2 & 6 & 2 & 6 & 2 & 6 & 2 & 6 & 2 & 6 \\
\hline ।,^ & $\mathrm{b}$ & $\mathrm{b}$ & $\mathrm{b}$ & $\mathrm{b}$ & b & b & b & $\mathrm{b}$ & b & $\mathrm{b}$ & bcd & b & $\mathrm{c}$ & $\mathrm{a}$ \\
\hline$\backslash, \mathrm{V}$ & $\mathrm{b}$ & de & $\mathrm{b}$ & $\mathrm{bc}$ & $\mathrm{b}$ & $\mathrm{b}$ & c & de & $\mathrm{b}$ & $\mathrm{cd}$ & $\mathrm{b}$ & $\mathrm{b}$ & $\mathrm{e}$ & $\mathrm{c}$ \\
\hline$\wedge,-$ & de & hij & de & def & $\mathrm{cd}$ & c & i & $\mathrm{jk}$ & fg & ij & $\mathrm{h}$ & de & $\mathrm{k}$ & $\mathrm{h}$ \\
\hline$\wedge, /$ & fg & 1 & fg & gh & $\mathrm{e}$ & d & 1 & no & $\mathrm{i}$ & $\operatorname{lm}$ & $\mathrm{j}$ & fgh & $\mathrm{p}$ & $\mathrm{k}$ \\
\hline$\wedge, 1$ & $\mathrm{~b}$ & $\mathrm{bc}$ & $\mathrm{b}$ & $\mathrm{bc}$ & $\mathrm{b}$ & $\mathrm{b}$ & $\mathrm{bc}$ & $\mathrm{bc}$ & $\mathrm{bc}$ & $\mathrm{bc}$ & $\mathrm{cd}$ & $\mathrm{b}$ & d & $\mathrm{b}$ \\
\hline$\wedge, \wedge$ & $\mathrm{cd}$ & fg & cde & d & $\mathrm{cd}$ & $\mathrm{c}$ & gh & hi & ef & fgh & $\mathrm{gh}$ & $\mathrm{cd}$ & $\mathrm{j}$ & $\mathrm{h}$ \\
\hline${ }^{\wedge}, \mathrm{V}$ & $\mathrm{cd}$ & ghi & $\mathrm{cd}$ & de & $\mathrm{cd}$ & c & fg & gh & de & fg & ef & $\mathrm{cd}$ & $\mathrm{i}$ & $\mathrm{g}$ \\
\hline $\mathrm{V},-$ & cde & ijk & cde & ef & $\mathrm{cd}$ & $\mathrm{c}$ & hi & $\mathrm{ijk}$ & ef & ghi & fg & de & $\mathrm{g}$ & $\mathrm{e}$ \\
\hline $\mathrm{V}, /$ & $\mathrm{f}$ & 1 & $\mathrm{f}$ & g & $\mathrm{e}$ & d & $\mathrm{k}$ & $\mathrm{m}$ & $\mathrm{h}$ & $\mathrm{k}$ & $\mathrm{i}$ & $\mathrm{f}$ & $\mathrm{r}$ & $\mathrm{m}$ \\
\hline $\mathrm{V}, \mathrm{I}$ & $\mathrm{b}$ & $\mathrm{e}$ & $\mathrm{b}$ & $\mathrm{c}$ & $\mathrm{b}$ & $\mathrm{b}$ & $\mathrm{cd}$ & $\mathrm{e}$ & $\mathrm{bc}$ & d & $\mathrm{bc}$ & $\mathrm{b}$ & $\mathrm{f}$ & d \\
\hline $\mathrm{V}, \wedge$ & $\mathrm{cd}$ & fgh & $\mathrm{cd}$ & de & $\mathrm{cd}$ & $\mathrm{c}$ & fg & gh & de & $f$ & $\mathrm{f}$ & $\mathrm{cd}$ & $\mathrm{h}$ & f \\
\hline $\mathrm{V}, \mathrm{V}$ & $\mathrm{cd}$ & hij & $\mathrm{c}$ & def & $\mathrm{c}$ & c & $\mathrm{fg}$ & hij & $\mathrm{d}$ & fghi & $\mathrm{e}$ & $\mathrm{cd}$ & $\mathrm{k}$ & $\mathrm{h}$ \\
\hline \multicolumn{15}{|c|}{$N=11$} \\
\hline,-- & hi & $\mathrm{h}$ & fgh & hi & $\mathrm{cd}$ & $\mathrm{fg}$ & $\mathrm{h}$ & $\mathrm{j}$ & gh & $\mathrm{g}$ & gh & ij & $\mathrm{k}$ & 1 \\
\hline,$- /$ & 1 & $\mathrm{k}$ & $\mathrm{i}$ & $\operatorname{lm}$ & $\mathrm{e}$ & $\mathrm{ij}$ & $\mathrm{k}$ & $\mathrm{m}$ & $\mathrm{k}$ & $\mathrm{j}$ & i & $\mathrm{mn}$ & $\mathrm{mn}$ & $\mathrm{n}$ \\
\hline,- 1 & $\mathrm{c}$ & $\mathrm{c}$ & $\mathrm{bc}$ & c & $\mathrm{b}$ & $\mathrm{cd}$ & $\mathrm{c}$ & $\mathrm{d}$ & c & $\mathrm{c}$ & $\mathrm{bc}$ & $\mathrm{cd}$ & $\mathrm{bc}$ & bc \\
\hline,$-^{\wedge}$ & ij & $\mathrm{h}$ & gh & ij & $\mathrm{cd}$ & gh & $\mathrm{h}$ & $\mathrm{j}$ & hi & $\mathrm{gh}$ & gh & $\mathrm{jk}$ & $\mathrm{h}$ & $\mathrm{g}$ \\
\hline,$- \mathrm{V}$ & $\mathrm{fg}$ & $\mathrm{fg}$ & def & $\mathrm{fg}$ & $\mathrm{cd}$ & ef & $\mathrm{fg}$ & $\mathrm{i}$ & f & $\mathrm{f}$ & efg & gh & $\mathrm{i}$ & $\mathrm{j}$ \\
\hline I,- & 1 & $\mathrm{k}$ & $\mathrm{i}$ & $\mathrm{m}$ & $\mathrm{e}$ & $\mathrm{ij}$ & $\mathrm{k}$ & $\mathrm{m}$ & $\mathrm{k}$ & $\mathrm{j}$ & $\mathrm{i}$ & $\mathrm{n}$ & 1 & $\mathrm{~m}$ \\
\hline I,I & $\mathrm{m}$ & 1 & $\mathrm{j}$ & $\mathrm{n}$ & $\mathrm{f}$ & $\mathrm{k}$ & 1 & $\mathrm{n}$ & 1 & $\mathrm{k}$ & $\mathrm{j}$ & o & $\mathrm{q}$ & $\mathrm{r}$ \\
\hline$/, 1$ & ef & $\mathrm{f}$ & def & $\mathrm{fg}$ & $\mathrm{cd}$ & ef & $\mathrm{e}$ & $\mathrm{h}$ & $\mathrm{e}$ & $\mathrm{e}$ & $\mathrm{de}$ & efg & $\mathrm{h}$ & 1 \\
\hline$I^{\wedge} \wedge$ & 1 & $\mathrm{k}$ & $\mathrm{i}$ & $\mathrm{m}$ & $\mathrm{e}$ & $\mathrm{j}$ & $\mathrm{k}$ & $\mathrm{m}$ & $\mathrm{k}$ & $\mathrm{j}$ & $\mathrm{i}$ & $\mathrm{n}$ & o & $\mathrm{p}$ \\
\hline I,V & $\mathrm{k}$ & $\mathrm{j}$ & $\mathrm{i}$ & $\mathrm{kl}$ & e & $\mathrm{ij}$ & $\mathrm{j}$ & 1 & $\mathrm{j}$ & $\mathrm{i}$ & $\mathrm{i}$ & $1 \mathrm{~m}$ & $\mathrm{~m}$ & no \\
\hline \,-- & $\mathrm{c}$ & $\mathrm{c}$ & $\mathrm{bc}$ & $\mathrm{c}$ & $\mathrm{b}$ & bcd & $\mathrm{c}$ & $\mathrm{c}$ & $\mathrm{cd}$ & $\mathrm{c}$ & $\mathrm{bc}$ & $\mathrm{c}$ & $\mathrm{a}$ & $\mathrm{a}$ \\
\hline$\backslash, /$ & $\mathrm{f}$ & $\mathrm{f}$ & de & ef & $\mathrm{c}$ & ef & $\mathrm{e}$ & $\mathrm{g}$ & $\mathrm{e}$ & e & $\mathrm{d}$ & ef & $\mathrm{g}$ & $\mathrm{k}$ \\
\hline$\backslash, \backslash$ & a & $\mathrm{a}$ & $\mathrm{a}$ & a & a & $\mathrm{a}$ & a & a & $\mathrm{a}$ & a & a & $\mathrm{a}$ & a & $a b$ \\
\hline$\backslash, \wedge$ & $\mathrm{d}$ & $\mathrm{d}$ & $\mathrm{c}$ & $\mathrm{d}$ & $\mathrm{b}$ & $\mathrm{d}$ & $\mathrm{d}$ & e & $\mathrm{d}$ & $\mathrm{d}$ & $\mathrm{bc}$ & $\mathrm{d}$ & $\mathrm{d}$ & $\mathrm{d}$ \\
\hline $1, \mathrm{~V}$ & $\mathrm{~b}$ & $\mathrm{~b}$ & $\mathrm{~b}$ & $\mathrm{~b}$ & $\mathrm{~b}$ & $\mathrm{~b}$ & $\mathrm{~b}$ & $\mathrm{~b}$ & $\mathrm{~b}$ & $\mathrm{~b}$ & $\mathrm{~b}$ & $\mathrm{~b}$ & $\mathrm{~b}$ & $\mathrm{c}$ \\
\hline$\wedge,-$ & $\mathrm{ij}$ & $\mathrm{h}$ & gh & ij & $\mathrm{d}$ & gh & hi & $\mathrm{j}$ & hi & gh & gh & $\mathrm{ijk}$ & $\mathrm{g}$ & $\mathrm{f}$ \\
\hline$\wedge, /$ & 1 & $\mathrm{k}$ & i & $\mathrm{m}$ & $\mathrm{e}$ & $\mathrm{j}$ & $\mathrm{k}$ & $\mathrm{m}$ & $\mathrm{k}$ & $\mathrm{j}$ & i & $\mathrm{n}$ & $\mathrm{p}$ & $q$ \\
\hline$\wedge, 1$ & $\mathrm{~d}$ & $\mathrm{~d}$ & $\mathrm{c}$ & $\mathrm{d}$ & $\mathrm{b}$ & $\mathrm{d}$ & $\mathrm{d}$ & f & $\mathrm{d}$ & $\mathrm{d}$ & c & $\mathrm{d}$ & $\mathrm{e}$ & $\mathrm{e}$ \\
\hline$\wedge, \wedge$ & $\mathrm{j}$ & $\mathrm{i}$ & $\mathrm{h}$ & $\mathrm{j}$ & $\mathrm{d}$ & $\mathrm{h}$ & $\mathrm{i}$ & $\mathrm{k}$ & $\mathrm{i}$ & $\mathrm{h}$ & $\mathrm{h}$ & $\mathrm{k}$ & $\mathrm{j}$ & $\mathrm{kl}$ \\
\hline$\wedge, \mathrm{V}$ & gh & $\mathrm{g}$ & efg & gh & $\mathrm{cd}$ & $\mathrm{fg}$ & $\mathrm{g}$ & $\mathrm{i}$ & fg & $\mathrm{f}$ & fgh & hi & $\mathrm{h}$ & hi \\
\hline $\mathrm{V},-$ & $\mathrm{fg}$ & $\mathrm{f}$ & def & $\mathrm{fg}$ & $\mathrm{cd}$ & ef & $\mathrm{f}$ & $\mathrm{i}$ & f & $\mathrm{f}$ & efg & fgh & $\mathrm{h}$ & $\mathrm{h}$ \\
\hline $\mathrm{V}, I$ & $\mathrm{k}$ & $\mathrm{j}$ & i & $\mathrm{k}$ & $\mathrm{e}$ & $\mathrm{i}$ & $\mathrm{j}$ & 1 & $\mathrm{j}$ & $\mathrm{i}$ & $\mathrm{i}$ & 1 & $\mathrm{n}$ & o \\
\hline $\mathrm{V}, \mathrm{I}$ & $\mathrm{b}$ & $\mathrm{b}$ & $\mathrm{b}$ & $\mathrm{b}$ & $\mathrm{b}$ & $\mathrm{bc}$ & $\mathrm{b}$ & $\mathrm{bc}$ & $\mathrm{b}$ & $\mathrm{b}$ & $\mathrm{b}$ & $\mathrm{b}$ & $\mathrm{c}$ & $\mathrm{d}$ \\
\hline $\mathrm{V}, \wedge$ & gh & $\mathrm{g}$ & efg & gh & $c d$ & $\mathrm{fg}$ & $\mathrm{fg}$ & $\mathrm{i}$ & $\mathrm{fg}$ & $\mathrm{f}$ & $\mathrm{fg}$ & hi & $\mathrm{h}$ & ij \\
\hline $\mathrm{V}, \mathrm{V}$ & $\mathrm{e}$ & $\mathrm{e}$ & $\mathrm{d}$ & $\mathrm{e}$ & $\mathrm{cd}$ & $\mathrm{e}$ & $\mathrm{e}$ & $\mathrm{gh}$ & $\mathrm{e}$ & e & def & $\mathrm{e}$ & $\mathrm{f}$ & hi \\
\hline
\end{tabular}




\section{References}

Akpınar S, Bayhan GM (2011) A hybrid genetic algorithm for mixed model assembly line balancing problem with parallel workstations and zoning constraints. Eng Appl Artif Intell 24:449-457. https ://doi.org/10.1016/j.engappai.2010.08.006

Altiok T, Stidham S (1983) The allocation of interstage buffer capacities in production lines. IIE Trans 15:292-299. https://doi.org/10.1080/05695558308974650

Anderson DR, Sellers BD, Shamma MM (1973) Simulation of Sequential Production Systems with Inprocess Inventory. In: Proceedings of the 6th conference on winter simulation. ACM, New York, NY, USA, pp 85-92

Assaf R, Colledani M, Matta A (2014) Analytical evaluation of the output variability in production systems with general Markovian structure. OR Spectr 36:799-835. https://doi.org/10.1007/s0029 1-013-0343-6

Azzi A, Battini D, Faccio M et al (2014) Inventory holding costs measurement: a multi-case study. Int J Logist Manag 25:109-132. https://doi.org/10.1108/IJLM-01-2012-0004

Barron Y (2015) Mean sojourn time in multi stage fork-join network: the effect of synchronization and structure. Int J Oper Res Inf Syst 6:80-99. https://doi.org/10.4018/IJORIS.2015070104

Battaïa O, Dolgui A (2013) A taxonomy of line balancing problems and their solutionapproaches. Int J Prod Econ 142:259-277. https://doi.org/10.1016/j.ijpe.2012.10.020

Battini D, Persona A, Regattieri A (2009) Buffer size design linked to reliability performance: a simulative study. Comput Ind Eng 56:1633-1641. https://doi.org/10.1016/j.cie.2008.10.020

Bhatnagar R, Chandra P (1994) Variability in assembly and competing systems: effect on performance and recovery. IIE Trans 26:18-31. https://doi.org/10.1080/07408179408966625

Bulgak AA (2006) Analysis and design of split and merge unpaced assembly systems by metamodelling and stochastic search. Int J Prod Res 44:4067-4080. https://doi.org/10.1080/00207540600564625

Colledani M, Matta A, Tolio T (2010) Analysis of the production variability in multi-stage manufacturing systems. CIRP Ann Manuf Technol 59:449-452. https://doi.org/10.1016/j.cirp.2010.03.142

Conway R, Maxwell W, McClain JO, Thomas LJ (1988) The role of work-in-process inventory in serial production lines. Oper Res 36:229-241

Das B, Garcia-Diaz A, MacDonald CA, Ghoshal KK (2010) A computer simulation approach to evaluating bowl versus inverted bowl assembly line arrangement with variable operation times. Int J Adv Manuf Technol 51:15-24. https://doi.org/10.1007/s00170-010-2614-6

Das B, Garcia-Diaz A, MacDonald CA, Ghoshal KK (2012) Evaluation of alternative assembly line arrangements with stochastic operation times: a computer simulation approach. J Manuf Technol Manag 23:806-822. https://doi.org/10.1108/17410381211253353

Davis LE (1965) Pacing effects on manned assembly lines. Int J Prod Res 4:171-184. https://doi. org/10.1080/00207546508919974

El-Rayah TE (1979) The effect of inequality of interstage buffer capacities and operation time variability on the efficiency of production line systems. Int J Prod Res 17:77-89. https://doi.org/10.1080/00207 547908919596

Gershwin SB (1991) Assembly/disassembly systems: an efficient decomposition algorithm for tree-structured networks. IIE Trans 23:302-314. https://doi.org/10.1080/07408179108963865

Hillier M (2013) Designing unpaced production lines to optimize throughput and work-in-process inventory. IIE Trans 45:516-527. https://doi.org/10.1080/0740817X.2012.706733

Hillier MS, Hillier FS (2006) Simultaneous optimization of work and buffer space in unpaced production lines with random processing times. IIE Trans 38:39-51. https://doi.org/10.1080/074081705002082 89

Hillier FS, So KC (1991) The effect of machine breakdowns and interstage storage on the performance of production line systems. Int J Prod Res 29:2043-2055. https://doi.org/10.1080/00207549108948066

Hopp WJ, Simon JT (1993) Estimating throughput in an unbalanced assembly-like flow system. Int J Prod Res 31:851-868. https://doi.org/10.1080/00207549308956762

Hudson S, McNamara T, Shaaban S (2015) Unbalanced lines: where are we now? Int J Prod Res 53:1895-1911. https://doi.org/10.1080/00207543.2014.965357

Hutchinson ST, Villalobos JR, Beruvides MG (1997) Effects of high labour turnover in a serial assembly environment. Int J Prod Res 35:3201-3224. https://doi.org/10.1080/002075497194354 
Inman RR (1999) Empirical evaluation of exponential and independence assumptions in queueing models of manufacturing systems. Prod Oper Manag 8:409-432. https://doi.org/10.1111/j.1937-5956.1999. tb00316.x

Jacobs JH, Etman LFP, Rooda JE (2003) Characterization of operational time variability using effective process times. IEEE Trans Semicond Manuf 16:511-520. https://doi.org/10.1109/TSM.2003.81521 5

Jeong KC, Kim YD (2000) Heuristics for selecting machines and determining buffer capacities in assembly systems. Comput Ind Eng 38:341-360. https://doi.org/10.1016/S0360-8352(00)00045-0

Jia Z, Zhang L, Arinez J, Xiao G (2016) Performance analysis of assembly systems with Bernoulli machines and finite buffers during transients. IEEE Trans Autom Sci Eng 13:1018-1032. https://doi. org/10.1109/TASE.2015.2442521

Kalir AA, Sarin SC (2009) A method for reducing inter-departure time variability in serial production lines. Int J Prod Econ 120:340-347

Kelton WD, Smith JS, Sturrock DT (2014) Simio and simulation: modeling, analysis, applications, 1st edn. Simio LLC, Sewickley

Lambrecht M, Segaert A (1990) Buffer stock allocation in serial and assembly type of production lines. Int J Oper Prod Manag 10:47-61. https://doi.org/10.1108/01443579010000736

Lau H-S (1992) On balancing variances of station processing times in unpaced lines. Eur J Oper Res 61:345-356. https://doi.org/10.1016/0377-2217(92)90363-E

Law A (2014) Simulation modeling and analysis, 5th edn. McGraw-Hill, New York

Leung JWK, Lai KK (2005) Analysis of strategies for installing parallel stations in assembly systems. Ind Eng Manag Syst 4:117-122

Li J, Blumenfeld ED, Huang N, Alden JM (2009) Throughput analysis of production systems: recent advances and future topics. Int J Prod Res 47:3823-3851. https://doi.org/10.1080/0020754070 1829752

Liu Y, Li J (2010) Split and merge production systems: performance analysis and structural properties. IIE Trans 42:422-434. https://doi.org/10.1080/07408170903394348

Maxwell WL (1970) Letter to the editor-on the generality of the equation $\mathrm{L}=\lambda \mathrm{W}$. Oper Res $18: 172-$ 174. https://doi.org/10.1287/opre.18.1.172

McNamara T, Shaaban S, Hudson S (2016) Fifty years of the bowl phenomenon. J Manuf Syst 41:1-7. https://doi.org/10.1016/j.jmsy.2016.07.003

Nahas N, Nourelfath M, Gendreau M (2014) Selecting machines and buffers in unreliable assembly/ disassembly manufacturing networks. Int J Prod Econ 154:113-126. https://doi.org/10.1016/j. ijpe.2014.04.011

Patti AL, Watson KJ (2010) Downtime variability: the impact of duration-frequency on the performance of serial production systems. Int J Prod Res 48:5831-5841. https://doi.org/10.1080/0020754090 3280572

Powell SG (1994) Buffer allocation in unbalanced three-station serial lines. Int J Prod Res 32:2201-2217

Powell SG, Pyke DF (1998) Buffering unbalanced assembly systems. IIE Trans 30:55-65. https://doi. org/10.1023/A:1007493512502

Purnomo HD, Wee H-M, Rau H (2013) Two-sided assembly lines balancing with assignment restrictions. Math Comput Model 57:189-199. https://doi.org/10.1016/j.mcm.2011.06.010

Romero-Silva R, Shaaban S (2019) Influence of unbalanced operation time means and uneven buffer allocation on unreliable merging assembly line efficiency. Int J Prod Res 57:1645-1666. https://doi. org/10.1080/00207543.2018.1495344

Romero-Silva R, Marsillac E, Shaaban S, Hurtado-Hernández M (2019) Serial production line performance under random variation: dealing with the 'Law of Variability'. J Manuf Syst 50:278-289. https://doi.org/10.1016/j.jmsy.2019.01.005

Sabuncuoglu I, Erel E, Gocgun Y (2006) Analysis of serial production lines: characterisation study and a new heuristic procedure for optimal buffer allocation. Int J Prod Res 44:2499-2523. https://doi. org/10.1080/00207540500465535

Schmenner RW, Swink ML (1998) On theory in operations management. J Oper Manag 17:97-113

Shaaban S, McNamara T, Dmitriev V (2017) Asymmetrical buffer allocation in unpaced merging assembly lines. Comput Ind Eng 109:211-220. https://doi.org/10.1016/j.cie.2017.05.008

Sivasankaran P, Shahabudeen P (2014) Literature review of assembly line balancing problems. Int J Adv Manuf Technol 73:1665-1694. https://doi.org/10.1007/s00170-014-5944-y

Slack N (1982) Work time distributions in production system modelling. Oxford Centre for Management Studies 
Smith LD, Brumbaugh P (1977) Allocating inter-station inventory capacity in unpaced production lines with heteroscedastic processing times. Int J Prod Res 15:163-172. https://doi.org/10.1080/00207 547708943114

Sönmez E, Scheller-Wolf A, Secomandi N (2017) An analytical throughput approximation for closed fork/join networks. INFORMS J Comput 29:251-267. https://doi.org/10.1287/ijoc.2016.0727

Tan B (1998) Agile manufacturing and management of variability. Int Trans Oper Res 5:375-388. https:// doi.org/10.1111/j.1475-3995.1998.tb00121.x

Tan B (2001) A three-station merge system with unreliable stations and a shared buffer. Math Comput Model 33:1011-1026. https://doi.org/10.1016/S0895-7177(00)00296-X

Tempelmeier H (2003) Practical considerations in the optimization of flow production systems. Int J Prod Res 41:149-170. https://doi.org/10.1080/00207540210161641

The R Foundation (2016) The R project for statistical computing. https://www.r-project.org/foundation/. Accessed 1 Jan 2020

Tolio TAM, Ratti A (2018) Performance evaluation of two-machine lines with generalized thresholds. Int J Prod Res 56:926-949. https://doi.org/10.1080/00207543.2017.1420922

Weiss S, Schwarz JA, Stolletz R (2018) The buffer allocation problem in production lines: formulations, solution methods, and instances. IISE Trans. https://doi.org/10.1080/24725854.2018.1442031

Wyche PDL, Wild R (1977) The design of imbalanced series queue flow lines. J Oper Res Soc 28:695702. https://doi.org/10.1057/jors.1977.145

Yegul MF, Erenay FS, Striepe S, Yavuz M (2017) Improving configuration of complex production lines via simulation-based optimization. Comput Ind Eng 109:295-312. https://doi.org/10.1016/j. cie.2017.04.019

Yuan X-M, Liu L (2005) Performance analysis of assembly systems with unreliable machines and finite buffers. Eur J Oper Res 161:854-871. https://doi.org/10.1016/j.ejor.2003.09.011

Publisher's Note Springer Nature remains neutral with regard to jurisdictional claims in published maps and institutional affiliations. 